\title{
Complementarity and Transition to Modern Economic Growth
}

\author{
Hyeok Jeong ${ }^{\dagger}$ and Yong Kim*
}

July 2010

\begin{abstract}
The Thai Socio-Economic Survey suggests that new labor market entrants increasingly enter occupational categories with high and positive productivity growth (modern sector), but continue to enter occupational categories with zero productivity growth (traditional sector). Workers appear to stick to their choice of entry between these two sectors throughout their work careers. We postulate that the transition from the traditional to modern sector is gradual because sector-specific work experience complements labor. We measure the technology parameters of each sector and the partition of the economy consistent with the identifying assumption of each sector (i.e. presence of productivity growth), by implementing a structural estimation on individual earnings equations. We verify the dual partition and sector specific complementarity do indeed exist. We then build a model of sectoral choice which simulates well the observed transition dynamics of workers across sectors at the estimated parameters.
\end{abstract}

JEL: O11, O47, J31

${ }^{*} \dagger$ International Development Studies, GRIPS; $\ddagger$ Department of Economics, Yonsei University. We appreciate the helpful comments from Robert Townsend, Robert E. Lucas Jr., Christopher Udry, Timothy Guinnane, Tee Kilenthong, Narayana Kocherlakota and the participants of various seminars and conferences at Duke, Yale, UCLA, UC Riverside, UC Santa Barbara, Vanderbilt University, Yonsei University, Boston University, Institute of Empirical Macroeconomics of the Federal Reserve Bank of Minneapolis, Society for Economic Dynamics Annual Meeting 2005, Conference on Microeconomics of Growth 2005 in Beijing (International Conference on Economic Development: China and the World), Pacific Conference for Development Economics 2006, North American Summer Meeting of the Econometric Society 2006, KAEA Annual Meeting of ASSA 2007 in Chicago, 2008 Korean Econometric Society Summer Camp Macroeconomics Meeting, and NBER Economic Growth Conference 2009 in San Francisco. We are grateful for the data obtained from the Thai National Statistical Office under collaboration with the Townsend Thai Project. Corresponding Email: jeong-hyeok@grips.ac.jp 
Keywords: experience-labor complementarity, structural transformation, transition dynamics, growth and inequality dynamics, modernization of Thailand 


\section{Introduction}

The Thai Socio-Economic Survey (a nationally representative household survey during 19761996) suggests that new labor market entrants increasingly enter occupational categories with high and positive productivity growth, which we label the "modern sector," but continue to enter into occupational categories with zero productivity growth, which we label the "traditional sector". Meanwhile, workers appear to stick to their choice of entry between these two sectors throughout their work careers. The coexistence of entry into these two sectors, identified by the presence or absence of productivity growth, is surprising because such a gap in growth implies a widening earnings gap between the two sectors over the lifetime of individuals in the same cohort. In particular, it seems puzzling that the transition of the labor force between these sectors should occur gradually, and is mainly driven by the increased entry of young workers.

We postulate that the transition from the traditional to modern sector is gradual because sector-specific work experience complements raw labor at an aggregate level. Under this complementarity, the scarcity of experience skill embodied in the old workers in the modern sector lowers the marginal product of labor of young workers, and limits their entry despite the prospect of higher productivity growth in the future. Meanwhile, today's young entrants in turn determine tomorrow's stock of experience. Thus, the transition to the exclusive use of modern technology occurs gradually (even though productivity grows only in the modern sector), while the sector specific nature of experience implies workers wish to stay in the sector they initially chose.

The quantitative role of our mechanism in explaining the gradual transition relies on the magnitude of the technology parameters of each sector and the dual sector partition of the economy consistent with the identifying assumption of each sector (i.e. presence of productivity growth). We explicitly measure our theory by implementing a structural estimation using the Thai Socio-Economic Survey. The technology parameters as well as the partition of economy into traditional and modern sectors are estimated using individual earnings equations derived from the model. We verify the dual partition and sector specific complementarity do indeed 
exist.

To assess the role of our mechanism in explaining the gradual transition, we build a simple model of sectoral choice which embeds the technological assumptions above, and study the transition dynamics of workers across sectors in Thailand. We feed technology estimates derived from the cross section of earnings, and simulate the sectoral entry decisions of agents over time. We find that the model simulated at the estimates can explain the observed gradual transition into the modern sector across cohorts. We also conduct a series of robustness checks informed by the standard errors of the estimates of the technology parameters.

Within each sector, fluctuations in the sectoral ratio of experience to labor will change the experience premium, generating within-sector earnings inequality dynamics. Between sectors, sector specific changes of the experience-labor ratio and the differential productivity growth rates across sectors will change the sectoral gap of average earnings, generating between-sector inequality dynamics. Thus, we provide an explicit link between growth and earnings inequality dynamics in a new way, through the factors that govern the transition dynamics.

The sectoral partition identified by our estimation implies that productivity grows at an annual average rate of $2.3 \%$ in the modern sector while it does not grow in the traditional sector. Figure 1 plots the cohort share of workers in the modern sector across cohorts identified by the first year when they enter the labor market, ranging between 1915 and 1996. This shows the coexistence of the two sectors over the 82 cohort years, and shows the slow monotonic transition among the early cohorts, followed by accelerated transition for the later cohorts. The share of modern sector workers was $6 \%$ among the 1915 cohort. This share increased only to $26 \%$ after forty years, and then had risen to $79 \%$ by 1996 . In contrast, we find for a given cohort, the sectoral shares do not change over different years of observation in the data (suggesting cohorts remain in the sector of entry over their lifetime, which we discuss in more detail later in Figure $3)$.

To demonstrate the presence of experience-labor complementarity, Figure 2 compares the movements of "returns to experience" and "average experience" over time for each sector (Figure 2.1 for the modern sector and Figure 2.2 for the traditional sector). The "returns to experience" 
are estimated from the standard Mincerian earnings equations. ${ }^{1}$ The "average experience" is measured by the aggregate years of work experience divided by the total number of workers for each sector. This shows that within-sector returns to experience rises when experience becomes scarce relative to raw labor, and vice versa. If experience simply adds on the effective unit of labor by substituting raw labor, the returns to experience should not respond to the changes in composition between experience and labor. These movements of average experience do not coincide with those of the total stock of experience so that these negative correlations are not due to simple diminishing returns to experience (see Figure A1 in Appendix). Figure 2 also shows that the movements of the returns to experience and the average experience differ substantially between the two sectors.

The paper is organized as follows. Section 2 reviews the related literature and discusses the contribution of this paper. Section 3 describes the model in three parts, first the technology, secnod, the implied individual earnings equations, then the model of sectoral choice associated with the equilibrium transition. Section 4 discusses the estimation procedure and results for the partition and technology parameters. Section 5 discusses the simulation procedure and results of the model of sectoral choice. Section 6 concludes.

\section{Contribution and Literature}

Chari and Hopenhayn (1991) consider theoretically the role of technology-specific complementarity between young and old workers in a vintage technology model, where new technologies arrive continuously. They study the steady state, which is unique and implies linear growth. We emphasize and characterize the transition dynamics across two technologies differentiated by productivity growth which we document using micro data along with experience-labor complementarity. $^{2}$

\footnotetext{
${ }^{1}$ The returns to experience are the estimates of the time-varying coefficients on experience in a log earnings equation controlling for observable characteristics such as years of schooling, gender, community type of residence, and geographic region, from the Thai Socio-Economic Survey. Direct information for actual work experience is not available in the Thai data and we follow the convention of the labor literature, measuring experience by potential experience, i.e. by (age - years of schooling - 6).

${ }^{2}$ Jovanovic and Nyarko (1996) analyze the transition dynamics of technology adoption in the context of Bayesian learning. Kremer and Thomson (1998) study a multi-sector economy where labor and skill from
} 
Dual-economy models featuring transition from a stagnant traditional sector to a growing modern sector were pioneered by Lewis (1954) and Ranis and Fei (1961). Unlike the assumptions of these early generation models, we consider all inputs to be priced at competitive margins in each sector, and assume constant returns to scale production technologies. Despite this, we show that the essential take-off dynamics can still be generated from the equilibrium transition dynamics, where the key premises of our model are consistent with data from a developing country, Thailand.

The related importance of structural transformation in understanding the growth process is emphasized by Kuznets (1966), and recently by Lucas (2000, 2004) and Galor (2005) among others. Parente and Prescott (2000), Gollin, Parente and Rogerson (2002), and Hansen and Prescott (2002) propose specific mechanisms that can explain the structural transformation as a gradual process, highlighting the role of external policy barriers by protecting the monopoly rights of interest groups, Stone-Geary type of non-homothetic preferences, or the existence of a fixed input such as land, respectively. We show gradual transition is also possible in the absence of these ingredients.

In particular, our model of transition is motivated by the earnings gap between coexisting sectors driven by differential productivity growth rates, and we propose a mechanism, experience-labor complementarity, which can explain this phenomenon. The same mechanism governs within-sector earnings inequality during transition, as the experience premium responds to movements of experience relative to labor. In this way, we highlight the link between transition and earnings inequality, both between sectors and within sectors. These considerations are absent in the related papers of dual economies or structural transformation. Our contribution is to document their presence and evaluate the quantitative importance of our proposed mechanism.

schooling are complements. In their models, the aggregate transition path to steady states is concave. We show when labor and skill from sector-specific experience are complements, the transition path will be convex before becoming concave, implying that aggregate earnings may be stagnant before taking-off. Beaudry and Francois (2005) study the possible multiple steady states (including poverty traps) in a dual economy model of complementarity between unskilled workers and skilled managers. In our model, the sustained productivity growth in the modern sector eventually overrides the persistent force of complementarity, implying a unique steady state. 
We also demonstrate how the key technology parameters of our mechanism can be estimated using the micro data. In particular, our empirical contribution is the identification of the traditional-modern dual economy partition, and measurement of technology parameters by estimating micro earnings equations which maintain consistent aggregation. Household or firm surveys do not directly collect data on the partition of an economy according to the use of traditional and modern technologies. Although the original idea of the dual economy is characterized by the absence or presence of productivity growth, the subsequent dual-economy literature often approximates this sectoral distinction by either product type (agriculture versus non-agriculture) or by community type (rural versus urban). We outline a novel method for identifying these sectors from earning equations based on the presence or absence of productivity growth. We show that under the identified partition, the traditional and modern sectors coexist within each subgroup of agriculture, manufacturing, services, as well as rural and urban areas in Thailand during 1976-1996.

Two papers by Jeong and Kim (2009) and Jeong, Kim and Manovskii (2009) study different issues using models related to the current paper. Jeong and Kim (2009) apply a related twoperiod model to explain the long-run evolution of per capita income and TFP across countries. In particular, they show that the relationship between initial TFP level and subsequent TFP growth among a sample of economies with "good-policies" is hump-shaped, emphasizing the S-shaped feature of aggregate TFP implied by the model. ${ }^{3}$ Moreover, they calibrate in their parameter selection without attempting to identifying the modern-traditional sector partition, due to the lack of detailed micro data over all countries. In contrast, the current paper shows how the coexistence of the two sectors and the presence of experience-labor complementarity can be precisely measured using the micro data from Thailand, and explains the observed gradual transition and the aggregate growth and inequality dynamics at such micro estimates.

Jeong, Kim and Manovskii (2009) study the micro data (the U.S. PSID) in a one-sector

\footnotetext{
${ }^{3}$ As in Lucas (2009), Jeong and Kim (2009) selected such a sample using the Sachs and Warner criterion for trade openness. They then link this to a pattern of aggregate TFP growth which is S-shaped and apply the related model to assess whether cross-country differences in the evolution of TFP can be accounted for quantitatively.
} 
model to highlight the role of experience-labor complementarity in explaining the U.S. earnings inequality dynamics. ${ }^{4}$ Their study is not motivated by the presence of the dual sectors with productivity growth differences, and therefore motivates experience-labor complementarity for different purposes. Instead, Jeong, Kim and Manovskii (2009) study the role of demographic composition alone in explaining the returns to two different components of human capital, i.e. work experience and schooling, when experience complements labor. ${ }^{5}$

\section{Model}

\subsection{Technology}

Here we outline the technology which embodies our assumptions of the dual economy and experience-labor complementarity. Consider a $J$-period overlapping-generations economy. There are $J$ different cohorts with varying years of experience $j$ from $j=0$ to $j=J-1$ at a given date. There are two sectors, traditional and modern, indexed by $k$ ( $k=T$ for traditional sector and $k=M$ for modern sector), associated with different technologies that produce a homogenous good.

The youngest agent $(j=0)$ is endowed with one unit of raw labor that is inelastically supplied to either sector. This agent acquires a sector-specific skill from the work experience, and supplies this sector-specific experience skill and raw labor in a bundle next period when $j=1 .^{6}$ The effective units of experience change according to the years of experience $j$ within

\footnotetext{
${ }^{4}$ This is a characterization of the U.S. economy consistent with the current paper if we view the U.S. as having completed modern transition.

${ }^{5}$ Critical to their approach is the presence of data on actual experience. With the actual experience data available, they show that a much richer characterization of the efficiency units of labor and experience is possible and also that movements of the returns to schooling are related to the movements of the returns to experience through the demographic compositional changes among cohorts. In the current paper, we are working with potential experience data only which differentiates our characterization of labor and experience from their paper.

${ }^{6}$ In our model, each agent supplies a bundle of inputs of raw labor and experience, and cohorts can differ in their relative supply of these inputs as they age, but maintaining the number of types of inputs as two, regardless of the number of period of generations $J$.

In contrast, in related vintage human capital OLG models, e.g. Chari and Hopenhayn (1991), young and old workers are considered to supply different complementary inputs in a two-period overlapping generations framework. If following this modeling choice, the types of inputs (hence the number of state variables of the model and possibly the dimension of complementarity) should expand as the number of period of generations $J$ increases. Our model provides a more natural way to specify the complementarity between younger and older
} 
sector $k$ according to the efficiency schedule of $\lambda_{k}(j)$. This efficiency schedule is introduced to capture the life-cycle variation of earnings.

Let $P_{t}$ denote the exogenous size of a cohort of workers who are born in the labor market at date $t$, and $N_{t}$ the mass of those cohort workers who enter the modern sector. $P_{t}-N_{t}$ is the mass of cohort workers entering the traditional sector. Then, the aggregate measures of labor $L_{M, t}$ and experience $E_{M, t}$ in the modern sector at date $t$ are given by

$$
\begin{gathered}
L_{M, t}=\sum_{j=0}^{J-1} N_{t-j}, \\
E_{M, t}=\sum_{j=0}^{J-1} \lambda_{M}(j) N_{t-j},
\end{gathered}
$$

and the aggregate measures of labor $L_{T, t}$ and experience $E_{T, t}$ in the traditional sector at date $t$ are given by

$$
\begin{gathered}
L_{T, t}=\sum_{j=0}^{J-1}\left(P_{t-j}-N_{t-j}\right), \\
E_{T, t}=\sum_{j=0}^{J-1} \lambda_{T}(j)\left(P_{t-j}-N_{t-j}\right) .
\end{gathered}
$$

The output in sector $k$ at date $t$ is produced by the following technology

$$
Y_{k, t}=\left(1+\gamma_{k}\right)^{t} F_{k}\left(L_{k, t}, E_{k, t}\right)
$$

where $F_{k}$ represents a sector-specific constant returns to scale technology combining the labor and experience, and $\gamma_{k}$ is the exogenous productivity growth rate of sector $k$. The identifying assumption between the two sectors is that the exogenous productivity grows only in the modern sector such that

$$
\gamma_{M}>\gamma_{T}=0
$$

Aggregate output at date $t$ is given by

$$
Y_{t}=Y_{M, t}+Y_{T, t}
$$

workers in the general $J$ period setting. 
In each sector, labor and experience are complements in the sense that

$$
\frac{\partial^{2} F_{k}\left(L_{k, t}, E_{k, t}\right)}{\partial E_{k, t} \partial L_{k, t}} \geq 0
$$

That is, more experience does not simply add on the effective unit of labor but rather increases the marginal product of labor.

\subsection{Earnings Equations}

Here we derive earnings equations implied by the technology which we will use to structurally

estimate the technology parameters in the estimation section. Begin by defining $f_{k}\left(\frac{E_{k, t}}{L_{k, t}}\right) \equiv$ $\frac{F_{k}\left(L_{k, t}, E_{k, t}\right)}{L_{k, t}}$, and the associated derivatives $\phi_{k}\left(\frac{E_{k, t}}{L_{k, t}}\right) \equiv f_{k}^{\prime}\left(\frac{E_{k, t}}{L_{k, t}}\right)$, and $\varphi_{k}\left(\frac{E_{k, t}}{L_{k, t}}\right) \equiv f_{k}\left(\frac{E_{k, t}}{L_{k, t}}\right)-$ $f_{k}^{\prime}\left(\frac{E_{k, t}}{L_{k, t}}\right) \frac{E_{k, t}}{L_{k, t}}$. Then the market prices of labor and experience for sector $k$ are respectively determined by the marginal products

$$
\begin{aligned}
& \frac{\partial Y_{k, t}}{\partial L_{k, t}}=\left(1+\gamma_{k}\right)^{t} \phi_{k}\left(\frac{E_{k, t}}{L_{k, t}}\right), \\
& \frac{\partial Y_{k, t}}{\partial E_{k, t}}=\left(1+\gamma_{k}\right)^{t} \varphi_{k}\left(\frac{E_{k, t}}{L_{k, t}}\right) .
\end{aligned}
$$

A worker with $j$ periods of work experience at date $t$ earns the sum of payments to the bundle of raw labor and experience skill $\lambda_{k}(j)$ in sector $k$ such that

$$
y_{k, t}(j)=\left(1+\gamma_{k}\right)^{t}\left[\phi_{k}\left(\frac{E_{k, t}}{L_{k, t}}\right)+\varphi_{k}\left(\frac{E_{k, t}}{L_{k, t}}\right) \lambda_{k}(j)\right],
$$

Defining the experience premium as the ratio of marginal product of experience to marginal product of labor

$$
\pi_{k}\left(\frac{E_{k, t}}{L_{k, t}}\right) \equiv \frac{\left(1+\gamma_{k}\right)^{t} \varphi_{k}\left(\frac{E_{k, t}}{L_{k, t}}\right)}{\left(1+\gamma_{k}\right)^{t} \phi_{k}\left(\frac{E_{k, t}}{L_{k, t}}\right)}=\frac{\varphi_{k}\left(\frac{E_{k, t}}{L_{k, t}}\right)}{\phi_{k}\left(\frac{E_{k, t}}{L_{k, t}}\right)},
$$

the earnings equation for sector $k$ can be expressed as

$$
y_{k, t}(j)=\left(1+\gamma_{k}\right)^{t} \phi_{k}\left(\frac{E_{k, t}}{L_{k, t}}\right)\left[1+\pi_{k}\left(\frac{E_{k, t}}{L_{k, t}}\right) \lambda_{k}(j)\right] .
$$

Note that experience-labor complementarity defined in (6) implies that $\phi_{k, t}$ increases in $\frac{E_{k, t}}{L_{k, t}}$ while $\varphi_{k, t}$ decreases in $\frac{E_{k, t}}{L_{k, t}}$. Thus, the experience premium $\pi_{k, t}$ is negatively correlated with the 
ratio of experience to labor $\frac{E_{k, t}}{L_{k, t}}$ within each sector when experience complements labor. This is the testable implication that we will use in measuring the complementarity parameters of the sector-specific technologies.

\subsection{Equilibrium Transition}

Here we specify a model of sectoral choice, which characterizes equilibrium transition dynamics of workers across sectors. This model will be simulated in section 5 to evaluate the quantitative importance of our mechanism in explaining the observed transition dynamics of labor force shifts as well as the earnings growth and inequality dynamics in Thailand. Note that this model of equilibrium transition will not be used in our parameter selection (estimation section $4)$.

Lifetime preferences of an agent who is born at date $t$ are

$$
U_{t}=\sum_{j=0}^{J-1} \beta^{j} c_{j, t+j},
$$

where $j$ denotes the age, $\beta \in(0,1)$ the time discount factor and $c_{j, t+j}$ the consumption of cohort $t$ at age $j$. The lifetime budget constraint is

$$
\sum_{j=0}^{J-1} \frac{c_{j, t+j}}{R_{t+j}}=\sum_{j=0}^{J-1} \frac{y_{j, t+j}}{R_{t+j}}
$$

where $R_{t+j}$ denotes the gross interest factor, $y_{j, t+j}$ the income of the cohort $t$ at age $j$. Linear preferences imply $R_{t+j}=\frac{1}{\beta^{j}}$. We assume agents have perfect foresight.

Our maintained assumption is that due to the sector-specificity of work experience, experienced workers do not switch sectors once they choose a sector when they enter the labor market. This is true as long as entry into both sectors is ongoing. Because the experience skill is sector specific, the opportunity cost of switching for experienced workers is strictly greater than that for the youngest workers. Meanwhile, when the two sectors coexist for a given cohort, the youngest workers are indifferent between sectors since lifetime earnings are equalized between the two sectors as we discuss below. In sum, experienced workers strictly prefer to stay in their sector when the youngest cohorts choose to enter both sectors. Along the transition path, there 
comes a point when the entire new cohort enters the modern sector only. We discuss conditions which ensure experienced workers never switch sectors for periods when the new entrants enter the modern sector only, in the discussion on equilibrium transition below.

From the earnings equation (7), the lifetime earnings $W_{k, t}$ of a cohort born in the labor market at date $t$ entering sector $k$ is given by

$$
W_{k, t}=\left(1+\gamma_{k}\right)^{t} \sum_{j=0}^{J-1} \beta^{j}\left(1+\gamma_{k}\right)^{j} \phi_{k}\left(\frac{E_{k, t+j}}{L_{k, t+j}}\right)\left[1+\pi_{k}\left(\frac{E_{k, t+j}}{L_{k, t+j}}\right) \lambda_{k}(j)\right] .
$$

A competitive equilibrium consists of a sequence of sectoral allocation of workers $\left\{N_{t}, P_{t}-N_{t}\right\}_{t=0}^{\infty}$ over the cohorts and interest factor $\left\{R_{t}\right\}_{t=0}^{\infty}$ such that

1. each agent earns his or her marginal products of labor and experience;

2. aggregate inputs are constructed from the sectoral allocation of workers according to equations (1) to (4);

3. young agents decide on a sector to work in and how much to consume to maximize their lifetime utility (8) subject to the lifetime budget constraint (9), and lifetime earnings are given by

$$
\max \left\{W_{M, t}, W_{T, t}\right\}
$$

where sectoral lifetime earnings $W_{k, t}$ is given by (10) for $k=M, T$;

4. credit market clears in every period, i.e. $R_{t}=\frac{1}{\beta}$ for all $t$ 's.

At an initial date $t=0$, the productivity growth occurs only in the modern sector, which motivates the transition of the labor force from traditional to modern sector. In an equilibrium where the two sectors coexist among the youngest cohort, the lifetime earnings should be equalized between the two sectors so that the workers are indifferent between the two sectors. That is, the equilibrium transition of labor force is characterized by the indifference condition 
$W_{M, t}=W_{T, t}$ or

$$
\begin{aligned}
& \left(1+\gamma_{M}\right)^{t} \sum_{j=0}^{J-1} \beta^{j}\left(1+\gamma_{M}\right)^{j} \phi_{M}\left(\frac{\sum_{h=0}^{J-1} \lambda_{M}(h) N_{t+j-h}}{\sum_{h=0}^{J-1} N_{t+j-h}}\right) \\
& \times\left[1+\pi_{M}\left(\frac{\sum_{h=0}^{J-1} \lambda_{M}(h) N_{t+j-h}}{\sum_{h=0}^{J-1} N_{t+j-h}}\right) \lambda_{M}(j)\right] \\
& \sum_{j=0}^{J-1} \beta^{j} \phi_{T}\left(\frac{\sum_{h=0}^{J-1} \lambda_{T}(h)\left(P_{t+j-h}-N_{t+j-h}\right)}{\sum_{h=0}^{J-1}\left(P_{t+j-h}-N_{t+j-h}\right)}\right) \\
= & \times\left[1+\pi_{T}\left(\frac{\sum_{h=0}^{J-1} \lambda_{T}(h)\left(P_{t+j-h}-N_{t+j-h}\right)}{\sum_{h=0}^{J-1}\left(P_{t+j-h}-N_{t+j-h}\right)}\right) \lambda_{T}(j)\right],
\end{aligned}
$$

where the identifying restriction $\gamma_{M}>\gamma_{T}=0$ is used, and the aggregate inputs $E_{k, t+j}$ and $L_{k, t+j}$ in the lifetime earnings equations in (10) are replaced by the equations in (1) to (4).

This is a system of difference equations of order $2(J-1)$ in $N_{t}$ given initial condition $\left\{N_{-j}\right\}_{j=1}^{J-1}$. Unlike the typical difference equations where the terminal conditions are given and simple backward induction can be applied, here, the terminal date when the transition is completed is endogenous. Suppose $\widehat{S}$ is the first cohort of which the entire cohort of workers enters the modern sector, i,e. $N_{\widehat{S}}=P_{\widehat{S}}$. Then, the following terminal condition should be satisfied for such a cohort $W_{M, t} \geq W_{T, t}$ or

$$
\begin{aligned}
&\left(1+\gamma_{M}\right)^{\widehat{S}} \sum_{j=0}^{J-1} \beta^{j}\left(1+\gamma_{M}\right)^{j} \phi_{M}\left(\frac{\sum_{h=0}^{J-1} \lambda_{M}(h) N_{\widehat{S}+j-h}}{\sum_{h=0}^{J-1} N_{\widehat{S}+j-h}}\right) \\
& \times\left[1+\pi_{M}\left(\frac{\sum_{h=0}^{J-1} \lambda_{M}(h) N_{\widehat{S}+j-h}}{\sum_{h=0}^{J-1} N_{\widehat{S}+j-h}}\right) \lambda_{M}(j)\right] \\
& \geq \quad \sum_{j=0}^{J-1} \beta^{j} \phi_{T}\left(\frac{\sum_{h=0}^{J-1} \lambda_{T}(h)\left(P_{\widehat{S}+j-h}-N_{\widehat{S}+j-h}\right)}{\sum_{h=0}^{J-1}\left(P_{\widehat{S}+j-h}-N_{\widehat{S}+j-h}\right)}\right) \\
& \quad \times\left[1+\pi_{T}\left(\frac{\sum_{h=0}^{J-1} \lambda_{T}(i)\left(P_{\widehat{S}+j-h}-N_{\widehat{T}+j-h}\right)}{\sum_{h=0}^{J-1}\left(P_{\widehat{S}+j-h}-N_{\widehat{S}+j-h}\right)}\right) \lambda_{T}(j)\right] .
\end{aligned}
$$

The same condition should be satisfied for the following $J-1$ cohorts, after which the entire labor force is in the modern sector at date $S^{*} \equiv \widehat{S}+J-1$. That is, there are $J$ terminal conditions to be satisfied together with the indifference condition in (11) that characterize the equilibrium transition dynamics. We also require conditions ensuring that there is no switching of sectors (from traditional to modern) once workers choose which sector to enter in the beginning of their career, between period $\widehat{S}$ and $S^{*}$ when there are no new entrants in the traditional sector. Sufficient conditions for non-switching during this particular period are described in the Appendix A.2. 
The algorithm to solve this difference equation system is as follows. Because of the endogeneity of the terminal date of transition, we use the following guess-and-verify method in computing the equilibrium transition. Note that $N_{-1}<P_{-1}$ for us to consider the transition to start from date 0 . Then, $S^{*} \geq J-1$.

Step 1: Guess $S^{*}=J-1$ (i.e. $\widehat{S}=0$ ). Then, $N_{t}=P_{t}, \forall t \geq 0$ given the initial condition $\left\{N_{-i}\right\}_{i=1}^{J-1}$. Verify this by checking whether inequality (12) holds for $N_{0}=P_{0}$ through to $N_{J-1}=P_{J-1}$. If these inequalities hold, $S^{*}=J-1$ and the equilibrium transition is solved. If any of these equalities do not hold, $S^{*}>J-1$. Then, go to Step 2.

Step 2: Given $\left\{N_{-i}\right\}_{i=1}^{J-1}$, guess that $N_{t}=P_{t}, \forall t \geq 1$ and $S^{*}=J$. Then, find $N_{0} \in$ $\left(0, P_{0}\right)$ using the indifference condition in (11) for $t=0$. The left hand side of this equation monotonically increases in $N_{0}$ and the right hand side monotonically decreases in $N_{0}$, hence there exists a unique $N_{0} \in\left(0, P_{0}\right)$ which solves this condition. Now verify if $N_{t}=P_{t}, \forall t \geq 1$ by checking whether the terminal condition (12) holds for $N_{1}=P_{1}$ through to $N_{J-1}=P_{J-1}$. If so, indeed $S^{*}=J$ and equilibrium is solved. If not, $S^{*}>J$. Go to Step 3 guessing $S^{*}=J+1$.

Step 3: Given $\left\{N_{-i}\right\}_{i=1}^{J-1}$, guess that $N_{t}=P_{t}, \forall t \geq 2$. Then determine $N_{1} \in(0,1)$ using the indifference condition in (11) for $t=1$. Given this solution $N_{1}$, find $N_{0}$ using the indifference condition in (11) for $t=0$. Check if the terminal condition (12) holds for $N_{2}=P_{2}$ through to $N_{J}=P_{J}$. If so, $S^{*}=J+1$. If not, guess $S^{*}=J+2$ and repeat the above procedure to solve out $N_{2}, N_{1}$ and $N_{0}$ and verify. Repeat this procedure until you find the equilibrium terminal date $S^{*}$.

The mass of modern sector workers $N_{t-j}$ is the key state variable of our model that endogenously evolves over time, given the initial condition $\left\{N_{-j}\right\}_{j=1}^{J-1}$ and the exogenous series of cohort size $P_{t}$.

\section{Estimation}

In this section, we measure the technology parameters (within-sector experience-labor complementarity and productivity growth) and the dual-sector partitioning by estimating the individual earnings equations (7) using the Thai Socio-Economic Survey (SES), a nationally rep- 
resentative household survey for the 1976-1996 period. Eight rounds (1976, 1981, 1986, 1988, 1990, 1992, 1994, and 1996) of repeated cross-sections were collected during this period, using clustered random sampling, stratified by geographic regions (Bangkok and its Metropolitan vicinity region, Central region, Northern region, Northeast region, and South region).

The SES categorizes total income into wage, profits, property income, and transfer income. The nominal income values are converted into real terms in 1990 baht value using the CPI indices differentiated by the regions above. The SES reports work status as employer, self-employed, employee, family worker, unemployed, or inactive. Combining the disaggregated income sources and work status data, we sort out earned income (i.e. wages for the employed workers and profits for the self-employed) from total income to construct our earnings measure. Property income and transfer income are all excluded in our measure of earnings, hence people who live only on these sources of income are excluded in our sample. We include only economically active people (excluding unemployed or inactive people) among the working-age population (age equal to or higher than 15) and the work experience ranging between 0 and 59. Given this selection rule, the size of our sample is 176,336 .

\subsection{Individual Earnings Equations}

We parameterize the sectoral production functions $F_{k}$ by the CES forms

$$
F_{k}\left(L_{k, t}, E_{k, t}\right)=X_{k}\left[L_{k, t}^{\rho_{k}}+\alpha_{k} E_{k, t}^{\rho_{k}}\right]^{\frac{1}{\rho_{k}}}, \text { for } k=M, T
$$

where $X_{k}$ is the sectoral productivity level parameter, $\alpha_{k}>0$ is a scale parameter, $\rho_{k} \leq 1$ is a complementarity parameter (elasticity of substitution between experience and labor is $\frac{1}{1-\rho_{k}}$ ). $X_{T}$ is normalized to unity, hence $X_{M}$ captures the productivity level of modern sector relative to traditional sector in the initial period. The marginal product of labor (net of productivity growth term $\left.\left(1+\gamma_{k}\right)^{t}\right)$ is

$$
\phi_{k}\left(\frac{E_{k, t}}{L_{k, t}}\right)=X_{k}\left[1+\alpha_{k}\left(\frac{E_{k, t}}{L_{k, t}}\right)^{\rho_{k}}\right]^{\frac{1}{\rho_{k}}-1},
$$

and the experience premium is

$$
\pi_{k}\left(\frac{E_{k, t}}{L_{k, t}}\right)=\alpha_{k}\left(\frac{E_{k, t}}{L_{k, t}}\right)^{\rho_{k}-1} .
$$


We specify the efficiency schedule of experience $\lambda_{k}(j)$ in a quadratic form such that

$$
\lambda_{k}(j)=j+\lambda_{k} j^{2},
$$

to capture its possible nonlinearity.

In our estimation, we allow for exogenous individual productivity $\xi_{i, t}$ that commonly affect the effective units of raw labor and experience. Thus, each agent $i$ who has worked for $j$ periods in sector $k$ at date $t$ provides $\xi_{i, t}$ units of raw labor and $\xi_{i, t} \lambda_{k}(j)$ units of experience. This will capture the cross-sectional variation of earnings other than life-cycle variation in the data. We specify $\xi_{i, t}$ such that

$$
\xi_{i, t}=\exp \left[C \chi_{i, t}+\epsilon_{i, t}\right]
$$

where $\chi_{i, t}$ is a vector of observable characteristics like years of schooling, gender, community type of residence, and geographic region, $C$ measures the time invariant returns to those incomegenerating attributes and $\epsilon_{i, t}$ represents unobservable shocks drawn from a mean-zero i.i.d normal distribution over time $t$ 's and individual $i$ 's.

Substituting the above parameterized forms in equations (13) to (16) into the sector $k$ earnings equation in (7) and explicitly indexing all variables by individual $i$ and time $t$, our individual log-earnings equation for sector $k$ is

$$
\ln y_{k, i, t}=t \ln \left(1+\gamma_{k}\right)+\Phi_{k}\left(\frac{E_{k, t}}{L_{k, t}}\right)+\Pi_{k}\left(\frac{E_{k, t}}{L_{k, t}}, j_{i, t}\right)+C \chi_{i, t}+\epsilon_{i, t},
$$

where

$$
\begin{aligned}
\Phi_{k}\left(\frac{E_{k, t}}{L_{k, t}}\right) & =\ln X_{k}+\left(\frac{1}{\rho_{k}}-1\right) \ln \left[1+\alpha_{k}\left(\frac{E_{k, t}}{L_{k, t}}\right)^{\rho_{k}}\right], \\
\Pi_{k}\left(\frac{E_{k, t}}{L_{k, t}}, j_{i, t}\right) & =\ln \left[1+\alpha_{k}\left(\frac{E_{k, t}}{L_{k, t}}\right)^{\rho_{k}-1}\left(j_{i, t}+\lambda_{k} j_{i, t}^{2}\right)\right] .
\end{aligned}
$$

These earnings equations do not presume the presence of a dual partition with differential productivity growth $\gamma_{k}$ across sectors nor a complementarity between experience and labor within each sector. It is possible that there does not exist a dual partition of the labor force with $\gamma_{k}$ which is significantly positive in one and zero in the other. It is also possible that the complementarity parameter $\rho_{k}$ be estimated not to be statistically different from 1 . 


\subsection{Discussions of Earnings Equation}

Several comments are due about our earnings equation. First, when $\rho_{k}=1$ (i.e. experience and labor are perfect substitutes), this log earnings equation becomes a standard Mincerian type of log earnings equation: individual earnings are determined by individual characteristics not by aggregate state variables. However, when $\rho_{k}<1$, the individual earnings equation moves

depending on the aggregate state of the sector, $\frac{E_{k, t}}{L_{k, t}}$. The lower the $\rho_{k}$ parameter, the stronger the co-movement between the experience premium and the experience to labor ratio.

Second, the distinction between the modern and traditional sectors is recorded neither in national income accounting data nor in household or firm surveys. Thus, calibration of our key technology parameters using summary statistics or moment conditions is not feasible. However, explicit estimation of our individual earnings equation allows us to partition the economy into two sectors and also to measure the technology parameters.

Third, our individual earnings equation consistently aggregates to the aggregate production function. For the modern sector, we have

$$
\begin{aligned}
\sum_{j=0}^{J-1} y_{M, t}(j) & =\sum_{j=0}^{J-1} \sum_{i(j)=1}^{N_{t-j}}\left(1+\gamma_{M}\right)^{t} \phi_{M, t} \xi_{i(j), t}\left[1+\pi_{M, t} \lambda_{M}(j)\right] \\
& =\sum_{j=0}^{J-1} \sum_{i(j)=1}^{N_{t-j}}\left(1+\gamma_{M}\right)^{t}\left[\phi_{M, t} \xi_{i(j), t}+\varphi_{M, t} \lambda_{M}(j) \xi_{i(j), t}\right] \\
& =\left(1+\gamma_{M}\right)^{t}\left[\frac{\partial F_{M}}{\partial L_{M, t}} L_{M, t}+\frac{\partial F_{M}}{\partial E_{M, t}} E_{M, t}\right] \\
& =\left(1+\gamma_{M}\right)^{t} F_{M}\left(L_{M, t}, E_{M, t}\right) \\
& =Y_{M, t} .
\end{aligned}
$$

The fourth equality here is due to the constant returns to scale assumption for the aggregate production function. The third equality is true as long as the aggregate labor $L_{M, t}$ and aggregate 
experience $E_{M, t}$ are measured as

$$
\begin{aligned}
L_{M, t} & =\sum_{j=0}^{J-1} \sum_{i(j)=1}^{N_{t-j}} \xi_{i(j), t}, \\
E_{M, t} & =\sum_{j=0}^{J-1} \lambda_{M}(j) \sum_{i(j)=1}^{N_{t-j}} \xi_{i(j), t},
\end{aligned}
$$

which is key to consistent aggregation. Note that this requires knowledge about the efficiency schedule of experience $\lambda_{k}(j)$, and the returns to individual productive attributes $\xi_{i(j), t}$. A similar reasoning applies to consistent aggregation for the traditional sector.

Following from the third point, estimation of our log earnings equation data informs us about how to write the aggregate production function. In typical aggregate production functions, experience is considered as a human capital component which adds onto raw labor, i.e. increasing the effective units of labor. However, when experience and labor are complements, the between-sector as well as within-sector distributions of experience matters for aggregate earnings, the quantitative importance of which is determined by the degree of the complementarity.

\subsection{Identification of Parameters}

The parameters of the additively separable terms in the log-earnings equation (17), i.e. $\left\{\gamma_{k}, \lambda_{k}\right\}_{k=M, T}$ and $C$ are easily identified. The remaining parameters $\alpha_{k}$ and $\rho_{k}$ are identified from the two non-linear terms $\Phi_{k}\left(\frac{E_{k, t}}{L_{k, t}}\right)$ and $\Pi_{k}\left(\frac{E_{k, t}}{L_{k, t}}, j_{i, t}\right)$ in equations (18) and (19). Specifically, given $\alpha_{k}$, the complementarity parameter $\rho_{k}$ is identified from the time-series variation of experience premium $\alpha_{k}\left(\frac{E_{k, t}}{L_{k, t}}\right)^{\rho_{k}-1}$ in $\Pi_{k}\left(\frac{E_{k, t}}{L_{k, t}}, j_{i, t}\right)$ of the earnings equation in relation to the movements of $\frac{E_{k, t}}{L_{k, t}}$, consistently with the marginal product of labor $\Phi_{k}\left(\frac{E_{k, t}}{L_{k, t}}\right)$. The $\alpha_{k}$ is a time-invariant scale parameter, which is identified by the level relationship between average earnings and average $\frac{E_{k, t}}{L_{k, t}}$.

Note that the efficiency schedule parameters $\lambda_{k}$ and the coefficient vector $C$ for individual productivity attributes in log-earnings equation also affect the aggregate measures of labor and experience as in equations (20) to (21), which is key to consistent aggregation of our model, 
as discussed above. Thus, the estimates for such parameters should be consistent with those used in constructing the aggregate experience-labor ratio $\frac{E_{k, t}}{L_{k, t}}$, which in turn enters the $\log$ earnings equation. We use the following iterative procedure to achieve such consistency. We first measure the aggregate labor and experience within sectors setting $\lambda_{M}^{0}=\lambda_{T}^{0}=C^{0}=0$ at the initial round 0 and then estimate the log-earnings equation to obtain the first-round effective units parameters $\left\{\lambda_{M}^{1}, \lambda_{T}^{1}, C^{1}\right\}$. These are used to construct new experience-labor ratios to be used for the second-round estimation of the log-earnings equation. If the secondround estimates for the effective units parameters $\left\{\lambda_{M}^{2}, \lambda_{T}^{2}, C^{2}\right\}$ are the same as the first-round estimates $\left\{\lambda_{M}^{1}, \lambda_{T}^{1}, C^{1}\right\}$, we are done. Consistent aggregation is achieved. If not, repeat this iteration until they converge. We find that the convergence is indeed achieved.

Note that our estimation identifies the technology parameters using only the pooled individual earnings equation (17). We do not use any cohort transition dynamics and aggregate time-series data for earnings growth and inequality. We use such data for quantitative evaluation of our model using simulations later, thereby, separating the "data for estimation" from the "data for model evaluation". This way we can also avoid the well-known endogeneity bias problems of time-series estimation of aggregate production functions. Meanwhile, explicit estimation of parameters allows us to have the standard errors for the estimates of the technology parameters, which guides our sensitivity analysis.

\subsection{Identification of Partition}

Partitioning the labor force into traditional and modern sectors is another key measurement of our exercise. The partitions of the typical dual economy models such as agriculture versus non-agriculture or rural versus urban areas are observable in the data, while the partition of our model based on the productivity growth rate is not directly reported in the data. Using growth rates of income can be misleading for this partition, because the income growth is determined not only by the productivity growth rate $\gamma_{k}$, but also by the changes of the within-

sector experience to labor ratio $\frac{E_{k, t}}{L_{k, t}}$ through the marginal product of labor term $\Phi_{k}\left(\frac{E_{k, t}}{L_{k, t}}\right)$ as 
well as the experience premium term $\Pi_{k}\left(\frac{E_{k, t}}{L_{k, t}}, j_{i, t}\right)$ in equations (18) and (19). ${ }^{7}$ To estimate the productivity growth rates, we need to correctly measure the within-sector experience to labor ratio, which in turn requires the knowledge of the partition.

To solve out this circularity, we use the following guess-and-verify strategy. We first guess the partition using the simple implication of the model: traditional sector shrinks while modern sector expands. In forming the guess, we disaggregate the whole survey into 3-digit occupational categories, considering this detailed level of occupational category as a group of workers doing similar kinds of activities, and order the categories by rates of net growth in labor force share over the sample period, $1976-1996 .^{8}$

The model predicts that occupations with positive net entry rates are likely to be in the modern sector, and occupations with negative net entry rates are likely to be in the traditional sector. ${ }^{9}$ We guess a threshold level of rate of net entry around zero (starting with zero). Then, we estimate the log earnings equation (17) at the guessed partition. If our guess is correct for the Thai data, our estimates for the productivity growth rates should be consistent with the identifying restrictions of the partitioning, i.e. (i) $\gamma_{M}>\gamma_{T}$ and (ii) $\gamma_{T}=0$. This way we verify our guess. If the estimates of the productivity growth rates do not conform with the premises,

\footnotetext{
${ }^{7}$ The marginal product of labor increases in $\frac{E_{k, t}}{L_{k, t}}$ while the experience premium decreases in $\frac{E_{k, t}}{L_{k, t}}$. During transition, the experience to labor ratio tends to fall in modern sector and to rise in traditional sector, hence the marginal product of labor tends to fall and the experience premium tends to rise in modern sector, and vice versa in traditional sector. The net magnitudes on earnings of these effects are indeterminate. Despite the presence of the positive productivity growth only in modern sector, it is possible that traditional occupations may show higher income growth than the modern occupations, and we cannot use the simple observed income growth for our partition.

${ }^{8}$ Here, we make two kinds of adjustment in categorizing the occupational subgroups. First, the yearly sample size of about 22,300 is not large enough for every occupation category to have positive mass each year at this three digit level of disaggregation. Some occupational categories have too sparse samples. Calculating the growth rate of labor force share for such small cell occupations would be noisy. Thus, we merge these categories while still maintaining the similarity of their activities as much as possible. For example, we merge the physicists, chemists, biologists, and bacteriologists into a "scientists" group, economists, judges, curators and auctioneers to the "other professional workers" group, furnacemen and metal moulders to the "metal processors" group, trappers to the "hunting and fishing" category, chemical product mixers and petroleum refiners to the "chemical processors" group, tea/coffee/cocoa preparers and cigar makers to the "food processors" group. For the related reason of collecting occupations doing similar activities into one group, we also merged some categories to another. For example, we merge the rice farm workers to rice farmers.

${ }^{9}$ The labor force shares of traditional and modern occupations show monotonic decreasing and increasing trends throughout the sample period, as shown in Appendix Figures A2 and A3, although unsurprisingly the transitions patterns are noisier.
} 
we would adjust our threshold level, around zero, until we find the partition that is consistent with the identifying restrictions (if it exists). In fact, we find a threshold level of net entry rate precisely equal to zero satisfies this criterion.

Partitioning the entire sample into two groups with different productivity growth rates can be arbitrary. However, targeting the productivity growth rate of the low productivity growth group at the fixed value of zero gives us a discipline for our guess-and-verify procedure so that we avoid being ad hoc in measuring the partition of our model.

Note also that our way of dividing the entire sample into two groups based on compositional changes is simply one way of forming an initial guess for the partition. We do not restrict that the partition should be based on the compositional changes. The ultimate criterion of partitioning the economy into two sectors is still the differences in productivity growth rates, which is verified. Furthermore, we do not partition the economy in an ad hoc way to obtain the complementarity either. There is no reason to have strong complementarity within each sector, which is partitioned purely based on productivity growth.

\subsection{Results}

\subsubsection{Parameter Estimates}

We consider a 20-period OLG model over the observed range of experience years [0,59] in our simulation and accordingly group the experience $j$ by three years so that our experience variable $j \in\{0,1, \ldots, 19\}$. We also replace the scale parameter $\alpha_{k}$ by $\exp \left(\widetilde{\alpha}_{k}\right)$ to guarantee the positive sign restriction for $\alpha_{k}$ and estimate $\widetilde{\alpha}_{k}$ instead of $\alpha_{k}$ directly. Table 1 reports the nonlinearleast-squares estimates of the technology parameters in the log earnings equation (17) at our guessed partition based on the labor force share criterion, with standard errors in parentheses. ${ }^{10}$

${ }^{10}$ The estimates of the coefficients for the individual characteristics are
\begin{tabular}{|cccccccc|}
\hline constant & schooling & male & urban & North & South & Central & Bangkok \\
\hline \hline 5.633 & 0.138 & 0.613 & 0.461 & 0.172 & 0.556 & 0.555 & 0.845 \\
$(0.014)$ & $(0.001)$ & $(0.005)$ & $(0.009)$ & $(0.007)$ & $(0.009)$ & $(0.007)$ & $(0.010)$ \\
\hline
\end{tabular}


Table 1. Parameter Estimates

\begin{tabular}{|c|c|c|}
\hline Sector & Modern & Traditional \\
\hline \hline$\gamma_{k}$ & $0.023(0.0009)$ & $-0.001(0.0005)$ \\
$\rho_{k}$ & $-2.89(0.92)$ & $-13.73(0.80)$ \\
$\widetilde{\alpha}_{k}$ & $4.48(1.20)$ & $24.58(1.33)$ \\
$\lambda_{k}$ & $-0.0376(0.0006)$ & $-0.0276(0.0005)$ \\
$\ln X_{k}$ & $0.147(0.125)$ & 0 \\
\hline
\end{tabular}

Note: Number of observations $=176,336, R M S E=1.0504$, Adjusted $R^{2}: 0.4219$.

The estimates of the annual productivity growth are $\gamma_{M}=2.3 \%$ for the modern sector and essentially zero for the traditional sector. These estimates confirm not only the coexistence of two sectors of the economy with a substantial gap in productivity growth, but also the existence of a sector with complete absence of productivity growth.

The estimates of the complementarity parameters $\rho_{M}=-2.89$ and $\rho_{T}=-13.73$ imply that the elasticities of substitution between labor and experience are 0.257 for the modern sector, and 0.068 for the traditional sector. Thus, experience and labor strongly complement each other, and more so in the traditional sector.

The estimates for $\widetilde{\alpha}_{M}=4.48$ and $\widetilde{\alpha}_{T}=24.58$ imply that the scale parameters for experience relative to labor of our CES production function are $\alpha_{M}=\exp (4.48)=88$ and $\alpha_{T}=\exp (24.58)=4.7 E 10$. Note that the large numbers for these parameters do not imply that the share of raw labor in earnings are prohibitively tiny. Labor shares are determined by the combination of $\alpha_{k}$ and $\rho_{k}$ and also depend on the level of the labor-experience ratio. To be specific, the raw labor share for sector $k$ is given by

$$
\frac{\partial Y_{k, t}}{\partial L_{k, t}} \frac{L_{k, t}}{Y_{k, t}}=\left[1+\alpha_{k}\left(\frac{E_{k, t}}{L_{k, t}}\right)^{\rho_{k}}\right]^{-1} .
$$

The average raw labor shares at the above estimates are $17 \%$ and $33 \%$ for the modern and traditional sectors, respectively. Thus, our large estimates of $\alpha_{k}$ 's do not imply an odd configuration for the CES production function, although they suggest that a major part of earnings is attributed to experience.

At the estimated efficiency schedule parameters $\lambda_{k}$ in Table 1, the shapes of experienceearnings profiles turn out to differ between the two sectors. Appendix Figure A4 displays the 
estimated experience-earnings profiles for the two sectors. The modern sector profile displays a clear hump-shape peaking at experience group 13 (years of experience 39-41), as is consistent with the typical profiles that are observed in the labor literature for developed countries. The traditional sector profile is also concave, but interestingly it does not show a hump shape.

Finally, the estimate for $\ln X_{M}$ is statistically insignificant so that we set $\ln X_{M}=0$, implying $X_{M}=1$. (The productivity level parameter $X_{T}$ was normalized to one, hence $\ln X_{T}$ was set to zero.)

Given that we are using potential experience as our measure of years of work experience, we estimate the log earnings equation (17) using only the male sample as a robustness check for our estimates of the technology parameters, because the measurement error of using potential experience is likely to be smaller among males than females. We obtain similar estimates of technology parameters from the male only sample estimation, as reported in Appendix Table A1.

\subsubsection{Modern-Traditional Partition}

Figure 3 illustrates the cohort shares in the modern sector, where the horizontal axis indexes the year when the workers are born in the labor market and the vertical axis measures their labor force shares in the modern sector according to our partition. There are eight series of the modern cohort share data, each corresponding to each round of sampling year. The range of cohorts present in each round differs across rounds. This allows us to compare say the modern cohort share of entrants in 1976 observed in 1976 versus the cohort share of entrants in 1976 observed in 1996. The "average" in Figure 3 is the average of the modern cohort shares of the overlapping cohorts over the rounds, which is the series already shown in Figure 1 in the introduction. The "smoothed" is the nonparametric estimate of the smoothed line of "average" data. $^{11}$

This Figure suggests several interesting observations. First, despite the gap in productivity growth of $2.3 \%$ per year across sectors (and the implied divergence of earnings over the life-cycle

\footnotetext{
${ }^{11}$ We use the local polynomial fitting method to estimate the nonlinear trend choosing the bandwidth and weighting function following the Lowess procedure.
} 
between the two sectors), only $6 \%$ of the earliest cohort (1915 cohort) worked in the modern sector. Second, the overall transition, was substantial. The modern cohort share increased to $79 \%$ among the latest cohort (1996 cohort). Third, the process of transition has been monotonic but non-linear. The transition was slow until the 1960 cohort, after which convex acceleration followed.

Finally, Figure 3 shows that modern transition was driven by the entry decisions of new labor market entrants. If workers of a cohort moved into the modern sector as they got older, we should observe a systematic upward drift of the modern cohort share data over time. Figure 3 does not display such systemic movements, and the observations of cohort share measured in different sample years is remarkably consistent. ${ }^{12}$

Our only identifying assumption for sector partitioning is the presence or absence of productivity growth. Thus, our modern sector does not necessarily correspond to urban areas or non-agriculture, as is typically proxied either in the dual economy models or in the structural transformation literature. Indeed, we find that the modern and traditional sectors coexist within each subgroup of the economy. Figure 4.1 shows that the share of labor force in the modern sector increased not only at the aggregate level but also within each community of urban, sanitary district, and rural areas. ${ }^{13}$ In other words, the modernization in Thailand is not simply an urban phenomenon.

Figure 4.2 illustrates the share of modern labor force by final product sector. In manufacturing modernization is monotonic and the fastest, from $48 \%$ in 1976 to $80 \%$ in 1996 . In services, the modern sector expanded rapidly, followed by a decline between 1981 and 1986, and then resumed its expansion until 1996. Overall, the modern labor force share increased from $41 \%$ in 1976 to $66 \%$ in 1996. In agriculture, the traditional sector dominates. On average, only $4 \%$ of the agricultural labor force is in the modern sector. However, the share of modern sector also increased in agriculture, from $3.7 \%$ in 1976 to $5.3 \%$ in 1996.

\footnotetext{
${ }^{12}$ Kim and Topel (1995) document a similar finding that the shifts of labor force into industrial sectors are made by the youngest cohorts for Korea during 1970-1990.

${ }^{13}$ Sanitary districts in Thailand are the rural areas targeted by government for development. They are an intermediate community type between urban and rural areas reported in the Thai data.
} 
In sum, these observations suggest that (i) because of the level gap in modern labor share across subgroups, shifts of the labor force from rural to urban areas or from agriculture to non-agriculture would involve modernization, but also that (ii) the process of modernization has occurred within each subgroup of the economy.

\subsection{Earnings Inequality Dynamics}

The estimates of the technology parameters in Table 1 inform us of the aggregate production function within each sector. These estimates have implications for the within-sector as well as the between-sector inequality dynamics. We deal with each of these inequality implications in turn.

In the log earnings equation in (17), there are two observable sources of earnings inequality within each sector: (i) the inequality across experience groups, $\Pi_{k}\left(\frac{E_{k, t}}{L_{k, t}}, j_{i, t}\right)$, the main component of our model; and (ii) the inequality from the variation of the controls $C \chi_{i, t}$. The growth rate and marginal product terms are common to all workers within sectors. Figure 5 compares the movements of these two sources of within-sector inequality (first source labeled as "Model" and the second source labeled as "Controls") with those of the overall within-sector inequality in Thailand (labeled "Thai") for each sector. We use the Gini coefficient as our measure of within-sector inequality. ${ }^{14}$ Figure 5.1 shows that the Thai modern-sector earnings inequality rose and fell during the sample period, and this movement is driven by our model component $\Pi_{k}\left(\frac{E_{k, t}}{L_{k, t}}, j_{i, t}\right)$ for $k=M$ rather than the controls (which shows a flat movement). The inequality movement due to $\Pi_{k}\left(\frac{E_{k, t}}{L_{k, t}}, j_{i, t}\right)$ has two driving forces, first changes in within-sector experience premium in relation to $\frac{E_{k, t}}{L_{k, t}}$, and second the changes in the composition of experience groups. We find that the main force is the changes in experience premium due to the changes in experience-labor ratio over time. Figure 5.2 shows that the Thai traditional sector earnings in-

\footnotetext{
${ }^{14}$ The earnings due to the "Model" component is measured by $y_{k, i t}^{M o d e l}=\exp \left[\Pi_{k}\left(\frac{E_{k, t}}{L_{k, t}}, j_{i, t}\right)\right]$ since $\Pi_{k}$ is from the $\log$ earnings equation. The series for the Gini coefficient of the distribution of $y_{k, i t}^{M \text { odel }}$ over $i$ 's is the plot of the within-sector inequality for "Model". Similarly, we obtain the within-sector inequality for "Controls."

Note that the Gini coefficients for the two sources of inequality do not add up to the Gini coefficient for the total inequality because of the potential correlation between the individual characteristics and experience, as well as the presence of residuals.
} 
equality rose sharply for the first decade and then fell very moderately for the following decade. The initial sharp rise seems mainly driven by the big increase in $\Pi_{k}\left(\frac{E_{k, t}}{L_{k, t}}, j_{i, t}\right)$ for $k=T$ for the first decade. However, for the second decade, the two sources counteract each other. The inequality from the "Model" component fell but the inequality from the "Control" component continued to rise, and we observe almost a flat movement of the traditional sector inequality.

There are three observable sources of between-sector inequality: (i) changes due to the difference in labor productivity growth rates $\gamma_{k}$ 's between the modern and traditional sectors (labeled "Growth"); (ii) changes due to the different movements of experience-labor ratio (labeled "E/L") between the two sectors; and (iii) changes due to the compositional changes in control variables between the two sectors (labeled "Controls"). We use the modern sector average earnings relative to the traditional sector average earnings as our between-sector inequality measure. ${ }^{15}$ Figure 6 compares the between-sector earnings inequality in Thailand (labeled "Thai") with these three sources of inequality. Between-sector inequality in Thailand increased substantially from 1.5 in 1976 to 2.4 in 1992, followed by decline to 2.0 by 1996 . Figure 6 shows that this increasing trend in between-sector inequality is mainly due to the "Growth" effect. The movements of experience-labor ratios did not contribute to the changes in between-sector inequality. The different compositional changes in controls between the two sectors contribute to the changes in between-sector inequality only moderately.

\section{Simulation of Transition and Earnings Growth}

\subsection{Simulation Procedure}

We assess the model of equilibrium transition (section 3.3) in terms of its ability to generate the observed path of transition in modern cohort shares in Figure 3 over the sample period 1976-

\footnotetext{
${ }^{15}$ The average earnings of sector $k$ from "Growth" is obtained by $y_{k, t}^{G \text { row } t h}=X_{k}\left(1+\gamma_{k}\right)^{t}$ and the average earnings of sector $k$ in relation to "E/L" is obtained by $y_{k, t}^{E / L}=\exp \left[\Phi_{k}\left(\frac{E_{k, t}}{L_{k, t}}\right)+\overline{\Pi_{k}\left(\frac{E_{k, t}}{L_{k, t}}, j_{i, t}\right)}\right]$ where the upper bar denotes average over $i$ 's. The between-sector inequality due to "Growth" is $\frac{y_{M, t}^{G \text { row } t h}}{y_{T, t}^{G} \text { row } t h}$ and betweensector inequality due to "E/L" changes is $\frac{y_{M, t}^{E / L}}{y_{T, t}^{E / L}}$. Similarly, between-sector inequality from "Controls" effects is obtained using $C \overline{\chi_{i t}}$ for each sector.
} 
1996. Substantively, this amounts to comparing the transition path generated by equilibrium conditions (11) and (12) at the estimates of the technology parameters in Table 1, with the observed modern cohort share data. Recall, these conditions played no role in constructing the earnings equations that are used in selecting the model parameters. Thus, whether the transition of modern cohort shares simulated from these equations conform with observed cohort shares constitutes a test of the model of equilibrium transition.

Consistent with the estimation above, we simulate a 20-period overlapping generations model where one period in simulation corresponds to 3 calender years. We simulate the model at the estimated technology parameters of $\left\{\gamma_{k}, \rho_{k}, \alpha_{k}, \lambda_{k}, X_{k}\right\}$ for $k=T$ and $M$, as reported in Table 1. We set $\gamma_{T}=0$ following the identification of the traditional sector. $X_{T}=1$ by construction, and $X_{M}=1$ because the estimate for $\ln X_{M}$ is statistically insignificant. We investigated the manner by which cohort sizes vary in the data and found that the key source of variation was declining labor force participation for older experience groups. Conditioning on age we found that participation rates do not vary much between sample years. Thus, we model varying labor force participation rates $\left\{P_{j}\right\}_{j=0}^{J-1}$ which proxies the observed average labor force participation by experience group as shown in Appendix Figure A5.

The initial state $\left\{M_{-j}\right\}_{j=1}^{19}$ is set to the values of smoothed modern cohort shares in Figure 3, dating back to the cohort who entered the labor force in calender year 1915. This implies the simulation has calender year 1976 as $t=0$ for the model. In this way, we can assess the model performance in generating modern sector cohort entry when compared to the observed cohort share over the 1976-1996 sample period.

There remains a single free parameter to be pinned down, the time-discount factor $\beta$ (for every three years). Over the sample period, the annual real interest rate in Thailand was $10 \%$ on average associated with $\beta=0.72$ (implied by an annual discount factor of 0.9 ). ${ }^{16}$ We think it reasonable to regard this as an upper bound on the discount factor agents in the Thai economy apply to labor market decisions considering the possible borrowing constraints and risk aversion

\footnotetext{
${ }^{16}$ This is the time series average of the real financial lending rates in Thailand for the 1976-1996 period. (Source: Bank of Thailand)
} 
(particularly facing labor market entrants), which we assumed away. Thus, a priori we think that a range for $\beta$ below 0.72 , captures the discount factor of our model mapping to Thailand. ${ }^{17}$

Given the chosen parameters and the initial state, the series of modern cohort shares $\left\{M_{t}\right\}_{t=0}^{\widehat{S}}$ is simulated using (11) and (12), where $\widehat{S}$ is the endogenous first period when an entire cohort enters into the modern sector. Sectoral labor and experience, individual earnings, and sectoral and aggregate earnings are constructed in accordance with the simulated distributions of experience groups between the two sectors.

\subsection{Modern Transition}

Figure 7 compares the Thai modern cohort share with simulated modern cohort shares using three discount factors $\beta \in\{0.72,0.61,0.51\}$, associated with annual discount factors of $\{0.9,0.85,0.8\}$ respectively. Higher $\beta$ speeds up transition, and the model is quite successful in matching the level and slope of the observed modern cohort share for a discount factor in the neighborhood of $\beta=0.61$. On an annual basis, this is associated with a $5 \%$ higher discount rate than the discount rate on financial loans of $10 \%$, which we find permissible for reasons discussed above, and we consider $\beta=0.61$ as our benchmark. Overall, we conclude that the model simulated at the parameters estimated from the cross section earnings equations can generate the observed dynamics of modern sector transition for a reasonable discount factor. Using higher and lower discount factors of $\beta \in\{0.72,0.51\}$, both the trend and slope of the simulated cohort shares are typically robust to these changes, but the initial cohort share seems to deviate more than other cohort shares.

We perform further sensitivity analysis by varying the estimated technology parameters $\left\{X_{M},\left[\alpha_{k}, \rho_{k}, \gamma_{k}, \lambda_{k}\right]_{k=M, T}\right\}$ using the standard errors of the estimates in Table 1, and check the robustness of the simulation of modern cohort share. We vary the estimated technology parameters $\left\{X_{M}, \rho_{M}, \alpha_{M}, \rho_{T}, \alpha_{T}\right\}$ by plus and minus a half of one standard error. An exception is $X_{M}$, which is imprecisely estimated, hence we vary it by plus and minus $10 \%$.

\footnotetext{
${ }^{17}$ The magnitude of the discount factor early on in a workers career affects the simulation outcomes. We think that younger workers may face higher discount rates than middle aged or older workers which motivates thinking about $\beta \leq 0.72$.
} 
Figures reporting these results are shown in the Appendix.

Again, both the trend and slope of the simulated cohort shares are robust to these changes, but the initial cohort share seems to deviate more than other cohort shares. For example, higher $X_{M}$ speeds up transition, but the effect is through a higher modern sector cohort entry in the initial period, rather than through a steeper sloped entry for the entire transition path (as shown in Appendix Figure A6). Thus, as we vary technology parameters, the initial simulated shares appear to jump to values which subsequently direct the model to generate gradual cohort transition consistent with the data.

Transition also speeds up as $\rho_{M}$ decreases (stronger complementarity in modern sector) and $\alpha_{M}$ decreases (smaller the experience share in modern sector) as shown in Appendix Figure A7. Transition speeds up as $\rho_{T}$ increases (weaker complementarity in traditional sector) and $\alpha_{T}$ increases (larger the experience share in traditional sector) as shown in Appendix Figure A8. Overall, the simulation is more sensitive to varying the modern sector parameters $\left(\rho_{M}, \alpha_{M}\right)$ than traditional sector parameters $\left(\rho_{T}, \alpha_{T}\right)$. We can interpret the bands created by the simulations after changing the parameters by one half of one standard error as a kind of confidence interval for the simulated cohort transition path.

Finally, we also varied the other technology parameters $\left\{\gamma_{M}, \lambda_{T}, \lambda_{M}\right\}$ by one standard deviation, but the simulated outcomes hardly changed because the confidence interval itself is very tight for these estimates. As expected, higher $\gamma_{M}$ speeds up transition. Lower $\lambda_{T}$ and higher $\lambda_{M}$ tend to speed up transition as well.

\subsection{Earnings Growth}

From the simulated cohort entry, and the technology parameters $\left\{X_{M},\left[\alpha_{k}, \rho_{k}, \gamma_{k}, \lambda_{k}\right]_{k=M, T}\right\}$ for each sector, we can construct simulated within-sector and aggregate earnings growth. Figure 8 compares the simulated within-sector log earnings (labeled "Simul") with the log earnings in Thai data (labeled "Thai"), where we drop the residual terms in the log earnings equation (17) in construction of the data. Due to the difference in units of earnings between the model and the data, we index the simulated and Thai earnings to their initial year 1976 value. Note that 
simulated earnings do not have the exogenous control variables while the Thai earnings do. Thus, the differences in within-sector earnings growth between the simulation and the data are due to the growth in control variables within each sector. Figure 8 shows that the main patterns of within-sector earnings growth in the Thai data, i.e. the fast growth of the modern sector as well as the stagnation of the traditional sector, are well captured by our model. Furthermore, despite the long list of sources of growth due to exogenous controls, our model explains the magnitudes of within-sector earnings growth to a first order.

Figure 9 compares the aggregate earnings growth between the simulation (labeled "Simul") and the Thai data (labeled "Thai") in the same manner as the within-sector growth. Here, in contrast to the within-sector growth, the different compositional changes as well as the average level gap in controls between the traditional and modern sectors can be also important in accounting for the earnings growth. In fact, such effects are large in Thailand through the role of schooling in accounting for a large part of the aggregate earnings growth, as shown by the third line (labeled "School") in Figure 9. ${ }^{18}$ Observing the gap between the Thai data and the schooling growth effect, Figure 9 shows that our model accounts for most of the net Thai aggregate earnings growth very well. Our model explains why the aggregate earnings growth was low during the first decade and then rose during the second decade of the sample period.

\section{Conclusion}

Lucas (2004) states that "a useful theory of economic development will necessarily be a theory of transition." This paper assessed a theory of transition in a dual economy combined with the idea of sector-specific complementarity between experience and labor. We emphasize the role of work experience, which has not been considered as a major factor in the growth and development literature. In particular, the initial distribution of work experience between the traditional and modern sectors and the magnitudes of experience-labor complementarity determine the speed and slope of the growth process during transition.

\footnotetext{
${ }^{18}$ Compositional effects from other characteristics we controlled for such as regional migration and urbanization play a negligible role in the growth of aggregate earnings.
} 
We measured the theory using micro data from Thailand, where transition has occurred gradually out of a sector with no labor productivity growth to a sector with positive labor productivity growth. We estimated the partitioning of the sectors as well as the technology parameters from individual earnings equations. We verified the presence of the dual sector partition we propose along with complementarity between experience and labor within each sector. At these estimated partition and technology parameters, the model simulates well the gradual transition into the modern sector. These findings suggest that incorporating the concept of experience-labor complementarity in a dual economy sheds new light on understanding (i) individual earnings dynamics, (ii) construction of aggregate production function, and (iii) economies in transition.

\section{References}

[1] Beaudry, Paul and Patrick Francois (2005), "Managerial Skill Acquisition and the Theory of Economic Development," NBER Working Paper No. 11451.

[2] Chari, V.V., and Hugo Hopenhayn (1991), "Vintage Human Capital, Growth and the Diffusion of New Technology," Journal of Political Economy, vol. 99, no. 6, pp. 1142-1165.

[3] Galor, Oded (2005), "From Stagnation to Growth: Unified Growth Theory," Handbook of Economic Growth, North-Holland: Elsevier, pp.171-285.

[4] Gollin, Douglas, Stephen Parente and Richard Rogerson (2002), "The Role of Agriculture in Development," American Economic Review P\&P, pp. 160-164.

[5] Hansen, Gary and Edward C. Prescott (2002), "Malthus to Solow," American Economic Review, vol. 92, pp. 1205-1217.

[6] Jeong, Hyeok and Yong J. Kim (2009), "S-shaped Transition and Catapult Effects," mimeo.

[7] Jeong, Hyeok, Yong J. Kim, and Iourii Manovskii (2009), "The Price of Experience," mimeo.

[8] Jovanovic, Boyan, and Yaw Nyarko (1996), "Learning by doing and the Choice of Technology," Econometrica, V. 64: 1299-1310.

[9] Kim, Dae-Il and Robert Topel (1995), "Labor Market and Economic Growth: Lessons from Korea's Industrialization, 1970-1990," in Differences and Changes in Wage Structure, pp. 227-264, Richard Freeman and Lawrence Katz eds., Chicago and London: The University of Chicago Press. 
[10] Kremer, Michael and James Thomson (1998), "Why Isn't Convergence Instantaneous? Young Workers, Old Workers, and Gradual Adjustment," Journal of Economic Growth, March 3(1), pp. 5-28.

[11] Kuznets, Simon (1966), Modern Economic Growth, New Haven: Yale University Press.

[12] Lewis, W. Arthur (1954), "Economic Development with Unlimited Supplies of Labor," Manchester School of Economic and Social Studies, vol. 22, pp. 139-191.

[13] Lucas, Robert E. Jr. (2000), "Some Macroeconomics for the 21st Century," Journal of Economic Perspectives, vol. 14(1), pp. 159-168.

[14] Lucas, Robert E. Jr. (2004), "Life Earnings and Rural-Urban Migration," Journal of Political Economy, vol. 112, pp. S29-S59.

[15] Lucas, Robert E. Jr. (2009), "Trade and the Diffusion of the Industrial Revolution," American Economic Journal: Macroeconomics, V. 1(1): 1-25.

[16] Parente, Stephen and Edward C. Prescott (2000), Barriers to Riches, Cambridge: The MIT Press.

[17] Ranis, G. and J. Fei (1961), "A Theory of Economic Development," American Economic Review, vol. 51, pp. 533-565.

\section{A Appendix}

\section{A.1 Data Appendix}

Figure A1 plots the total and average experience stock within each sector, showing that the movements of the average stock of experience are not driven by the total stock of experience. This rules out the possibility that the negative correlations between the returns to experience and average experience in Figure 2 are driven by the diminishing returns to experience.

Figure A2 plots the series of labor force shares (indexed to the year 1976) of the ten largest occupations in our modern sector, and Figure A3 plots those of the ten largest occupations in our traditional sector. The combined labor force share of these occupations is $65 \%$ of the entire labor force (on average). These figures illustrate that the expansion of the modern sector and the decline of the traditional sector actively occurred at the occupation level throughout the sample period. That is, our initial partition of the economy into two sectors based on net compositional changes is not an accidental outcome of choosing the initial and end periods accordingly.

Figure A4 displays the estimated time-invariant experience-earnings profiles over the lifecycle for each sector.

Table A1 reports the nonlinear-least-squares estimates of the technology parameters using the male sample only ${ }^{19}$.

\footnotetext{
${ }^{19}$ The estimates of the coeffcients for the individual chracteristics are
} 


\section{Table A1. Parameter Estimates from Male Sample}

\begin{tabular}{|c|c|c|}
\hline Sector & Modern & Traditional \\
\hline \hline$\gamma_{k}$ & $0.020(0.0010)$ & $-0.005(0.0006)$ \\
$\rho_{k}$ & $-2.30(1.34)$ & $-21.05(1.33)$ \\
$\widetilde{\alpha}_{k}$ & $4.23(1.80)$ & $37.60(2.25)$ \\
$\lambda_{k}$ & $-0.0392(0.0006)$ & $-0.0302(0.0004)$ \\
$\ln X_{k}$ & $0.380(0.374)$ & 0 \\
\hline
\end{tabular}

Note: Number of observations $=107,829, R M S E=0.9629$, Adjusted $R^{2}: 0.3873$.

Figure A5 plots the fractions of the experience groups in the data, and also the approximated values used in simulation.

\section{A.2 Sufficient conditions for non-switching}

In period $t=\widehat{S}$, to ensure a traditional sector worker with $j=1$ periods of experience is not tempted to forgo his traditional sector experience and start over in the modern sector we require

$$
\begin{aligned}
& \left(1+\gamma_{M}\right)^{t} \sum_{j=1}^{J-1}\left[\beta\left(1+\gamma_{M}\right)\right]^{j-1} \phi_{M, t}\left[1+\pi_{M, t} \lambda_{M}(j-1)\right] \\
< & \sum_{j=1}^{J-1} \beta^{j-1} \phi_{T, t}\left[1+\pi_{T, t} \lambda_{T}(j)\right],
\end{aligned}
$$

be satisfied. This is a sufficient condition to ensure that in period $t=\widehat{S}$, traditional sector workers with $j>1$ periods of experience do not switch over (since they are more skilled in the traditional sector and have shorter time horizons). More generally, for periods $t=\widehat{S}$ to $\widehat{S}+J-2$, to ensure a traditional sector worker with $j=(t-\widehat{S}+1) \geq 1$ periods of experience is not tempted to start over in the modern sector we require

$$
\begin{aligned}
& \left(1+\gamma_{M}\right)^{t} \sum_{j=(t-\widehat{S}+1)}^{J-1}\left[\beta\left(1+\gamma_{M}\right)\right]^{j-(t-\widehat{S}+1)} \phi_{M, t}\left[1+\pi_{M, t} \lambda_{M}(j-(t-\widehat{S}+1))\right] \\
< & \sum_{j=(t-\widehat{S}+1)}^{J-1} \beta^{j-(t-\widehat{S}+1)} \phi_{T, t}\left[1+\pi_{T, t} \lambda_{T}(j)\right],
\end{aligned}
$$

be satisfied. We check all these $J-2$ conditions are satisfied in the simulation procedure.

\begin{tabular}{|ccccccc|}
\hline constant & schooling & urban & North & South & Central & Bangkok \\
\hline \hline 6.466 & 0.122 & 0.429 & 0.164 & 0.490 & 0.462 & 0.748 \\
$(0.014)$ & $(0.001)$ & $(0.010)$ & $(0.008)$ & $(0.010)$ & $(0.009)$ & $(0.012)$ \\
\hline
\end{tabular}




\section{A.3 Sensitivity Analysis Figures}

Figure A6 shows that higher $X_{M}$ speeds up transition, but the effect is through a higher modern sector entry in the initial period, rather than through a steeper sloped entry for the entire transition path. Figure A7 shows that transition also speeds up as $\rho_{M}$ decreases (i.e. stronger complementarity in modern sector) and $\alpha_{M}$ decreases (i.e. smaller the experience share in modern sector). Figure A 8 shows that transition speeds up as $\rho_{T}$ increases (i.e. weaker complementarity in traditional sector) and $\alpha_{T}$ increases (i.e. larger the experience share in traditional sector). 
Figure 1. Cohort Share of Modern Sector

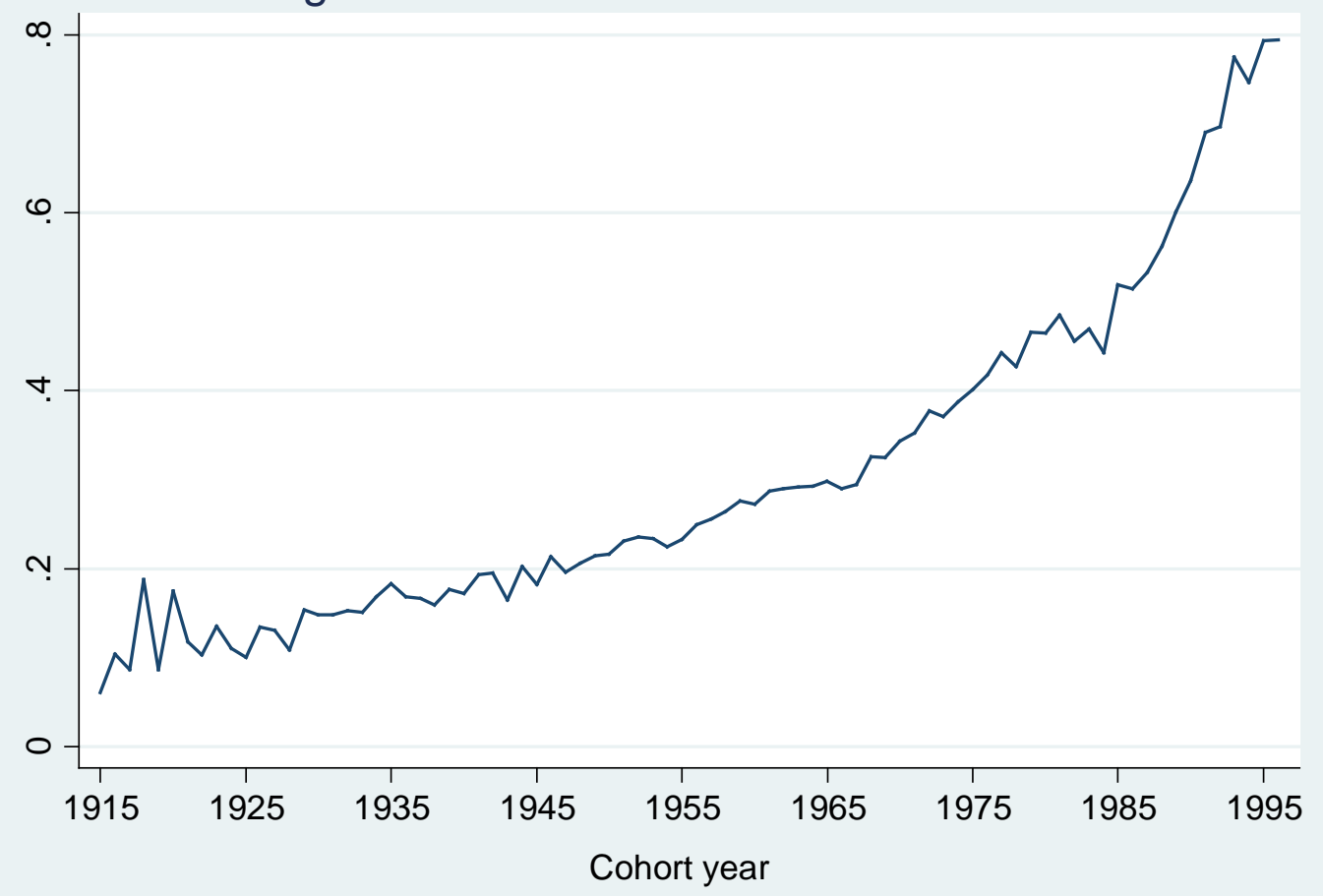

Figure 2. Movements of Returns to and Average of Experience

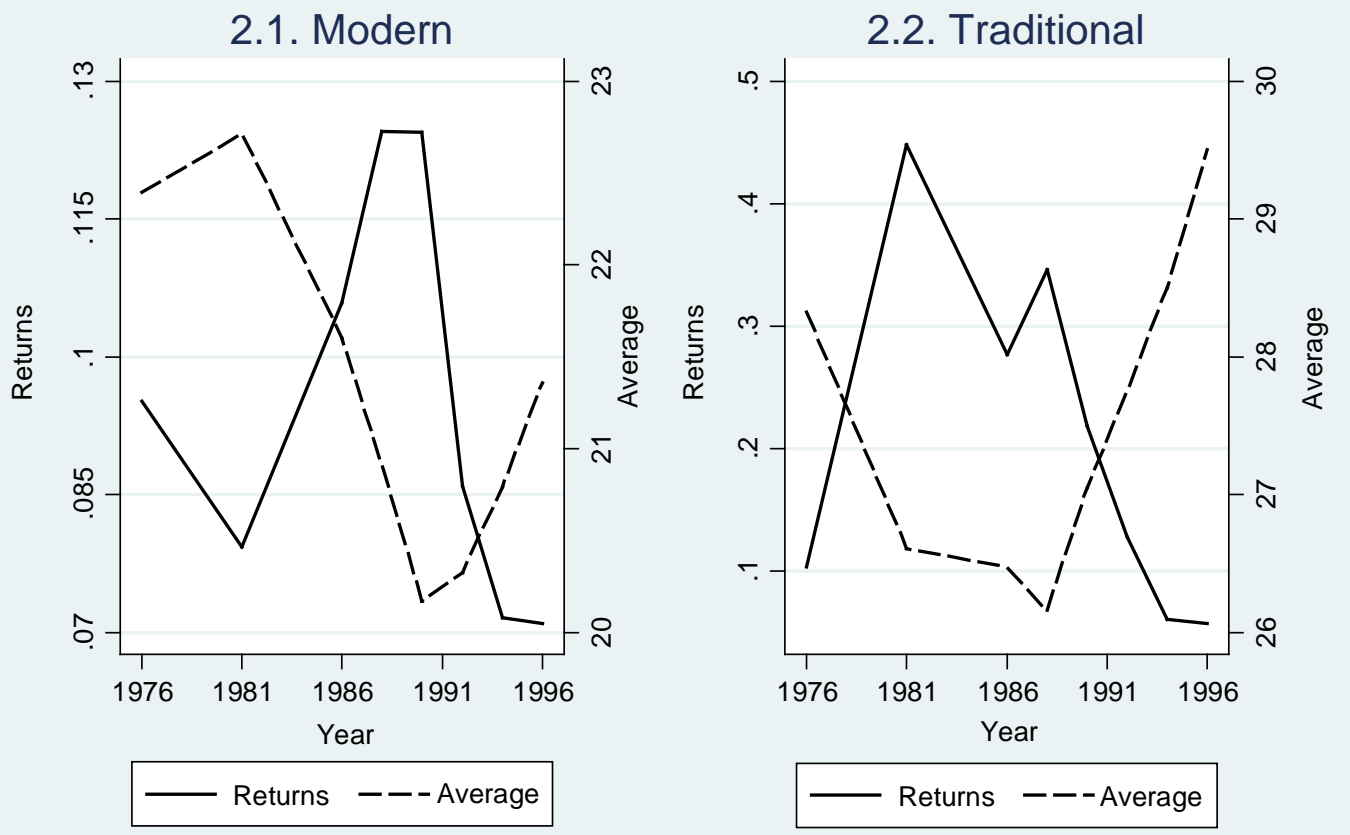


Figure 3. Modern Cohort Shares Over Sample Years

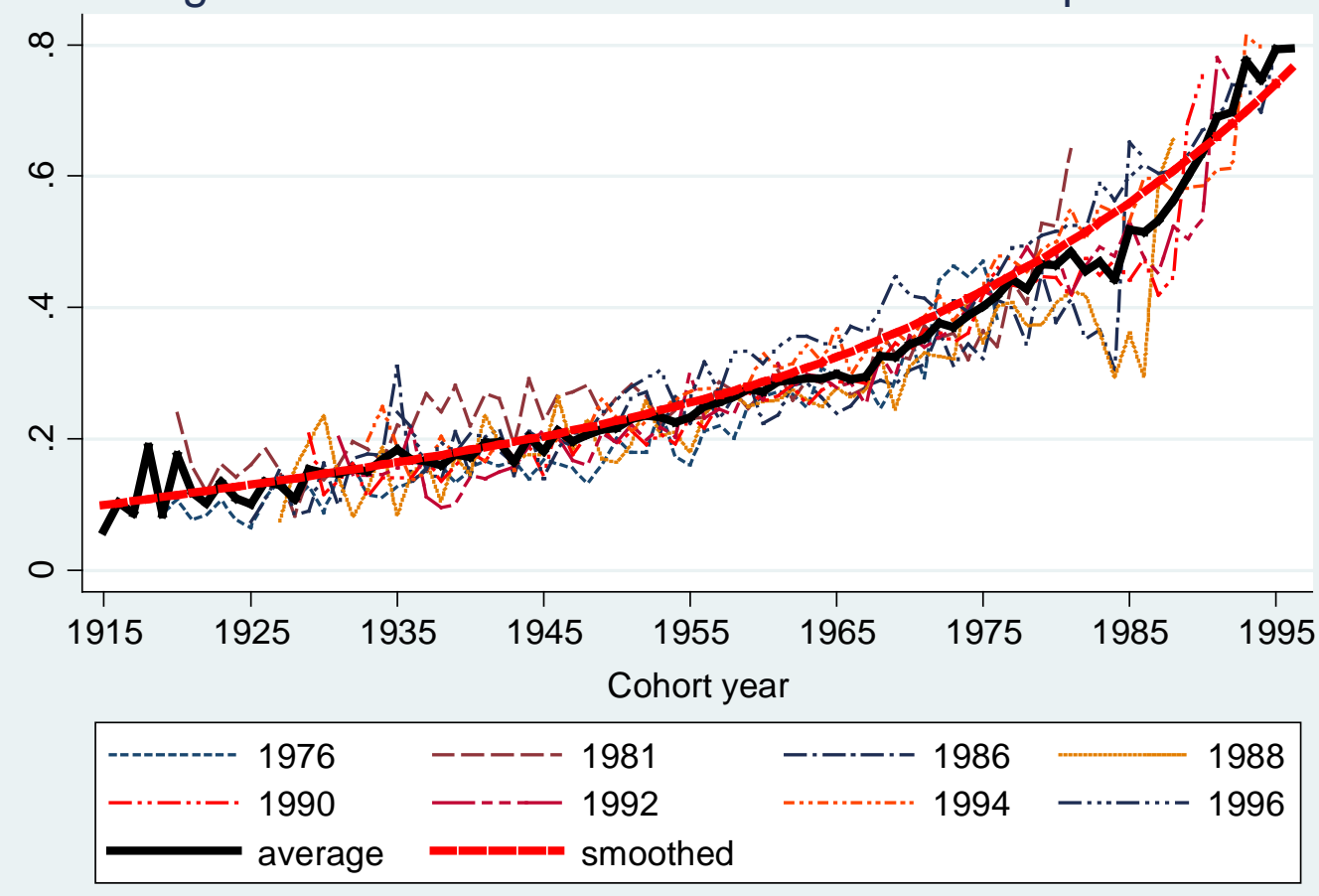

Figure 4. Modernization Within Subgroups

4.1. Within Community Type

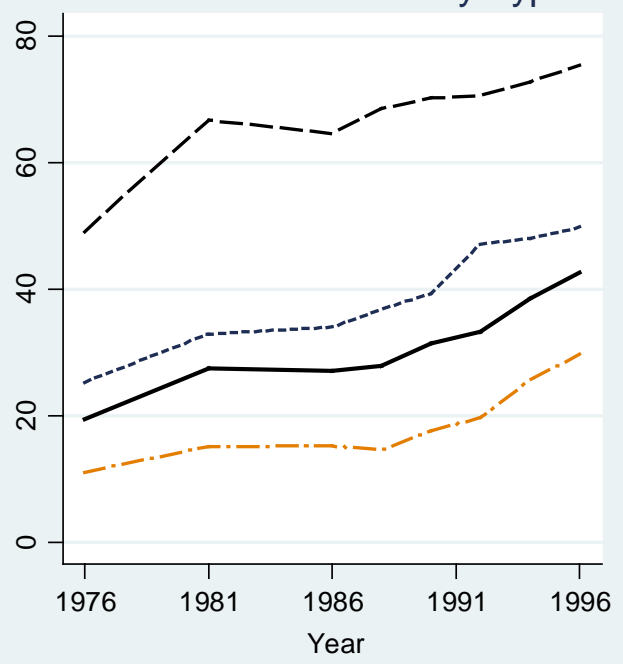

\begin{tabular}{|ll|}
\hline aggregate & $-ー-$ urban \\
------ sanitary district & $-\cdots-*$ rural
\end{tabular}

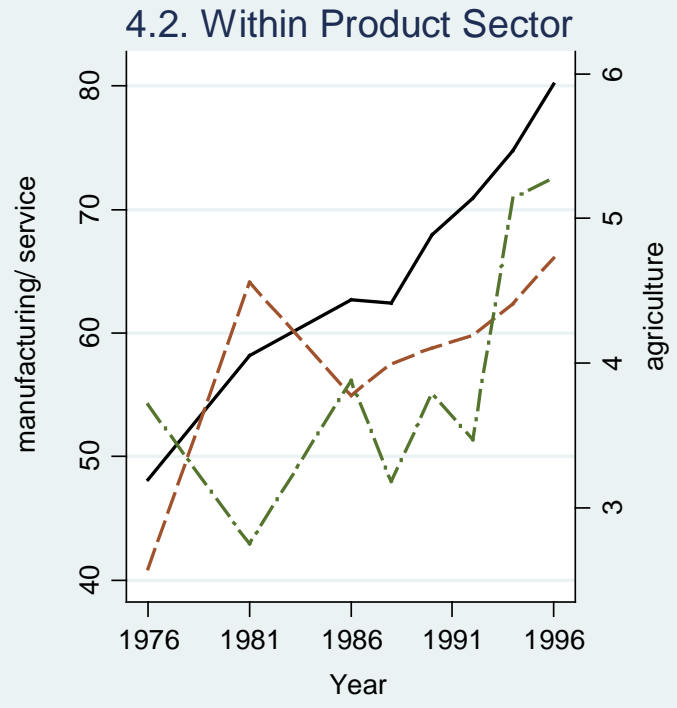

- manufacturing -- service
--- agriculture 
Figure 5. Within-sector Inequality Dynamics
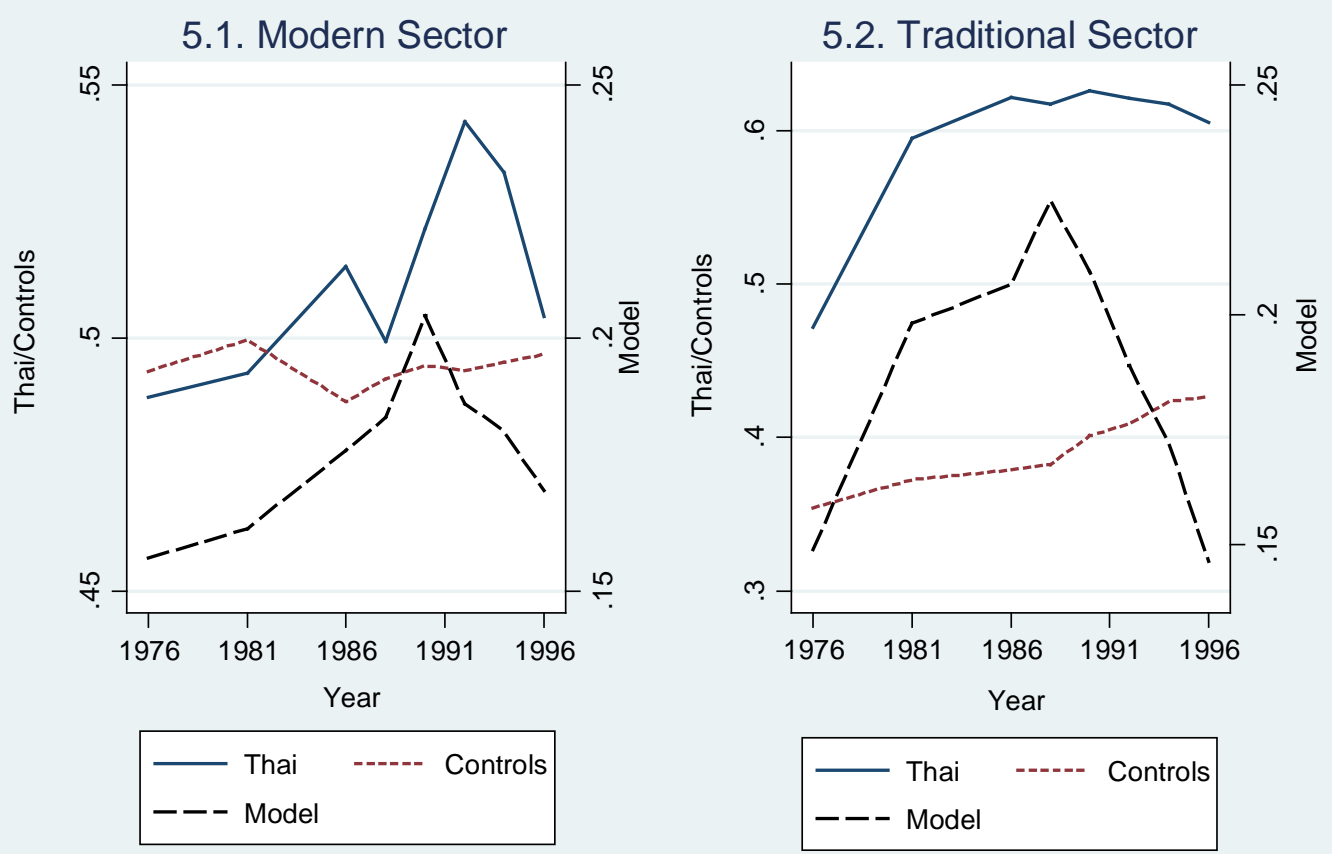

Figure 6. Between-sector Inequality Dynamics

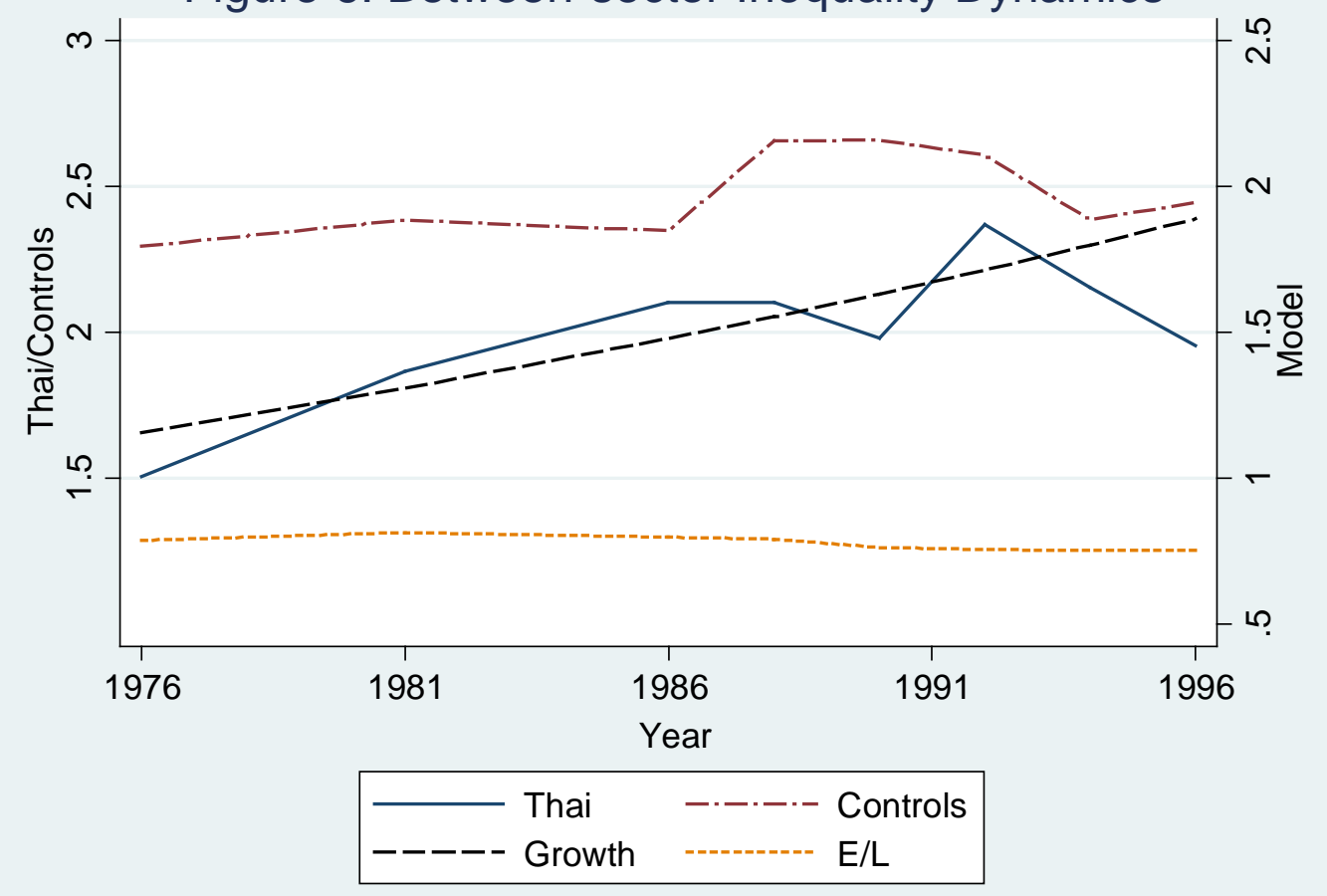


Figure 7. Simulated Modern Cohort Shares

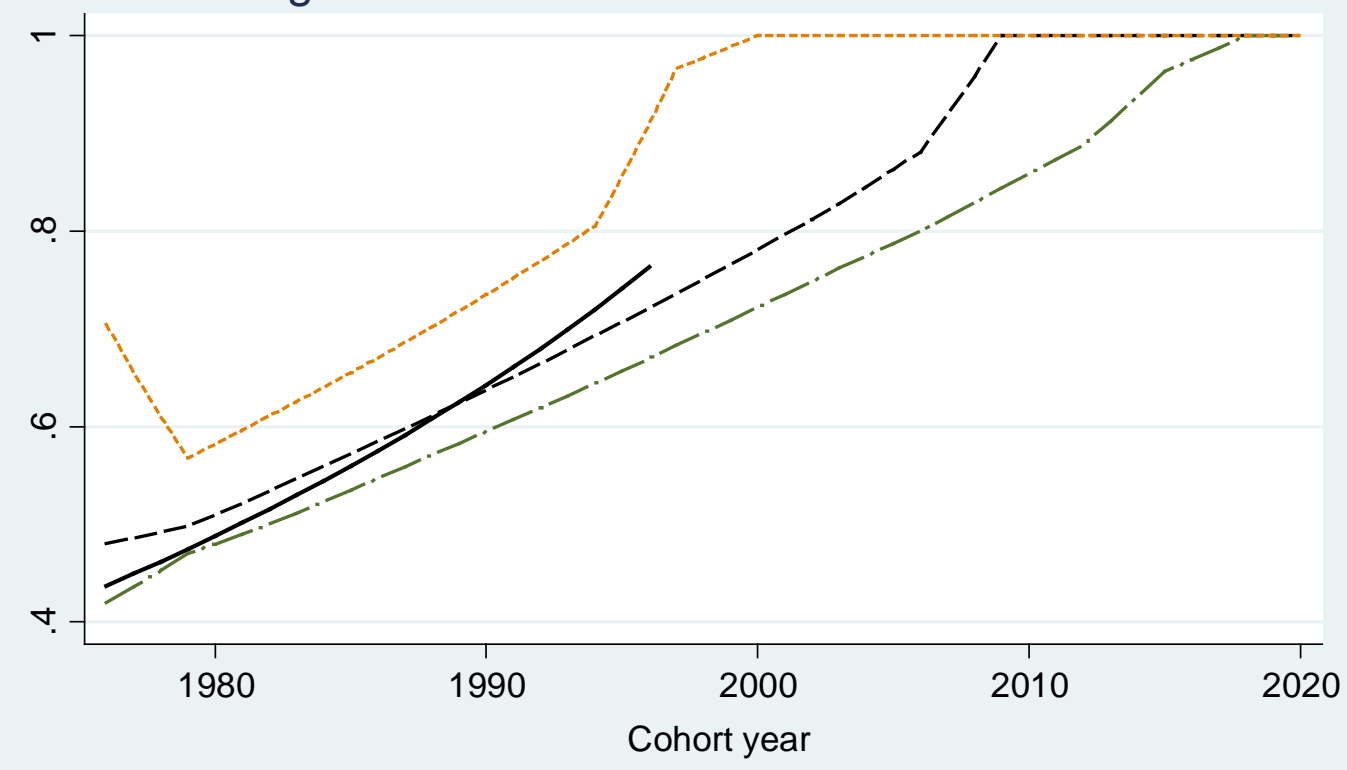

$\begin{array}{lll}\text { Thailand } & ----- \text { Simulation: } \text { beta }=0.61 \\ \text {-.-- Simulation: beta }=0.51 & ------- & \text { Simulation: } \text { beta }=0.72\end{array}$

\section{Figure 8. Within-Sector Earnings Growth}

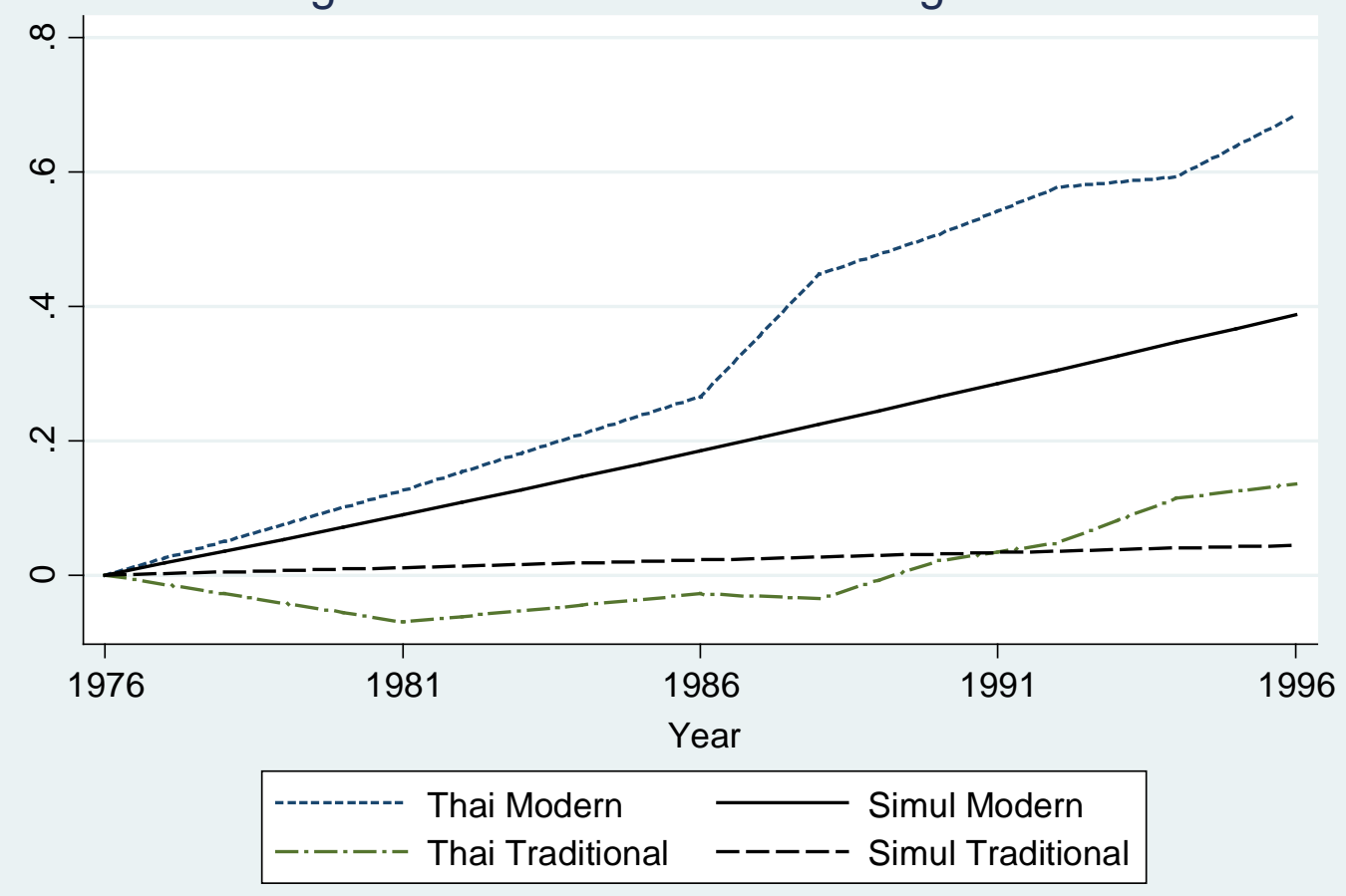


Figure 9. Aggregate Earnings Growth

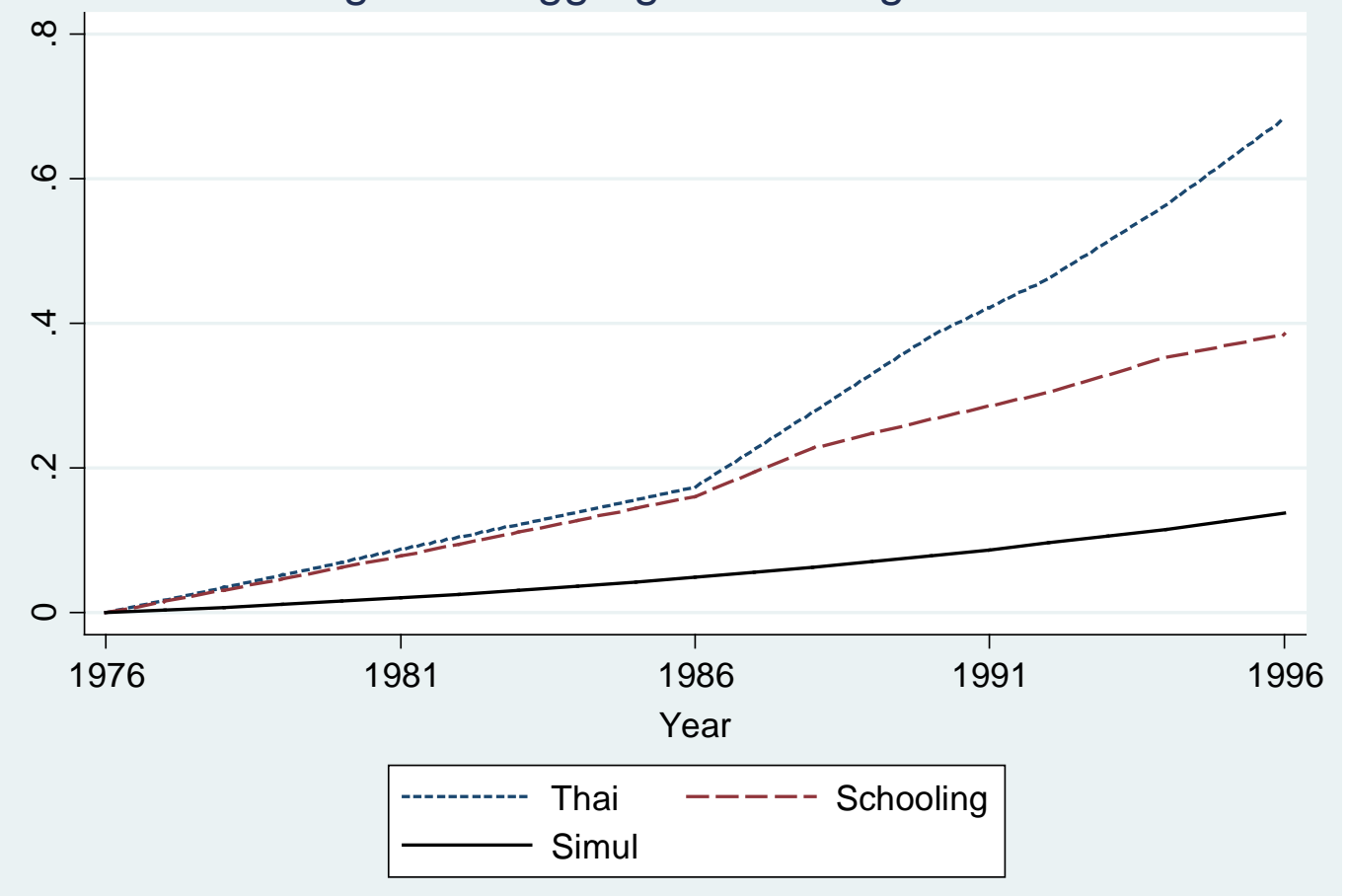


Figure A1. Movements of Average and Total Experience
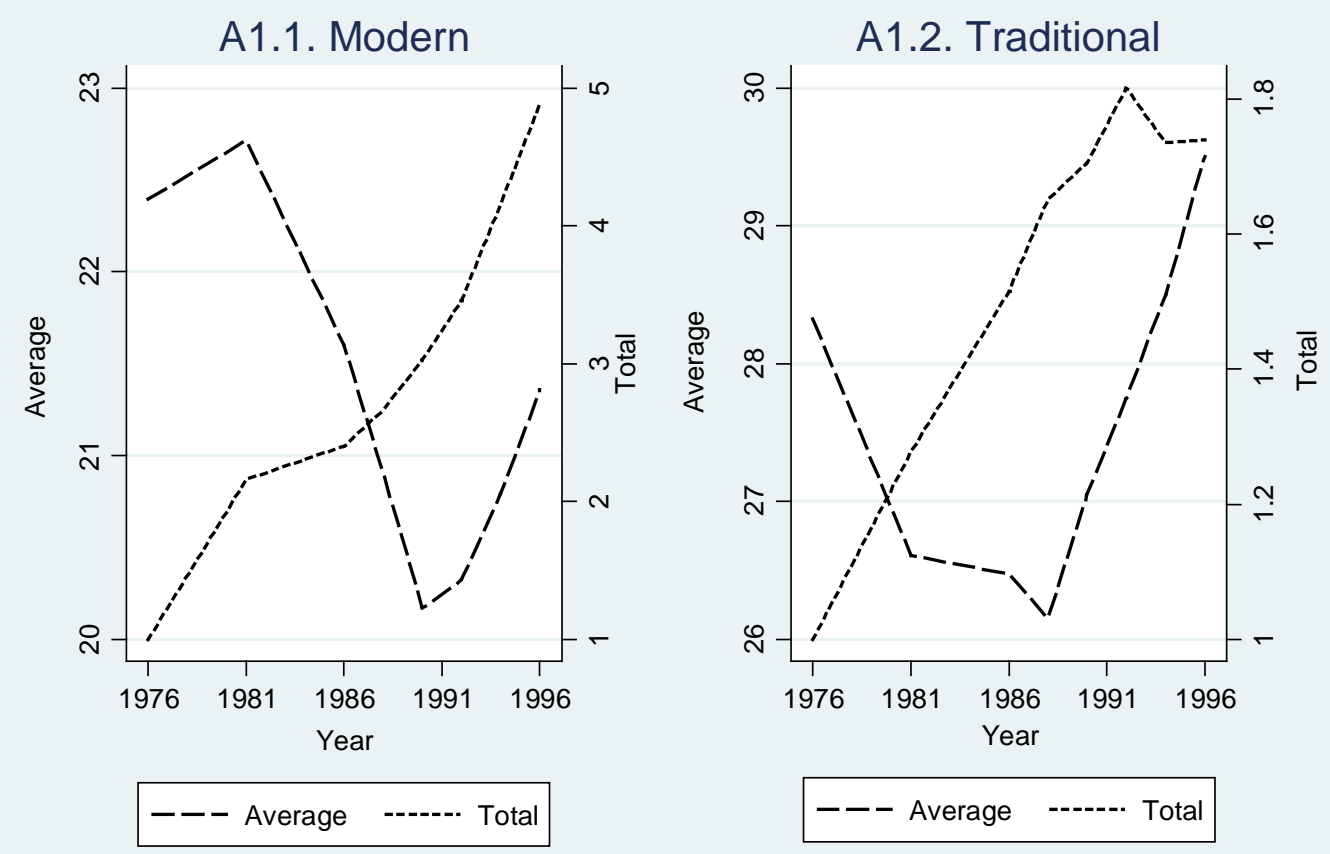

Figure A2. Population Shares of Modern Occupations

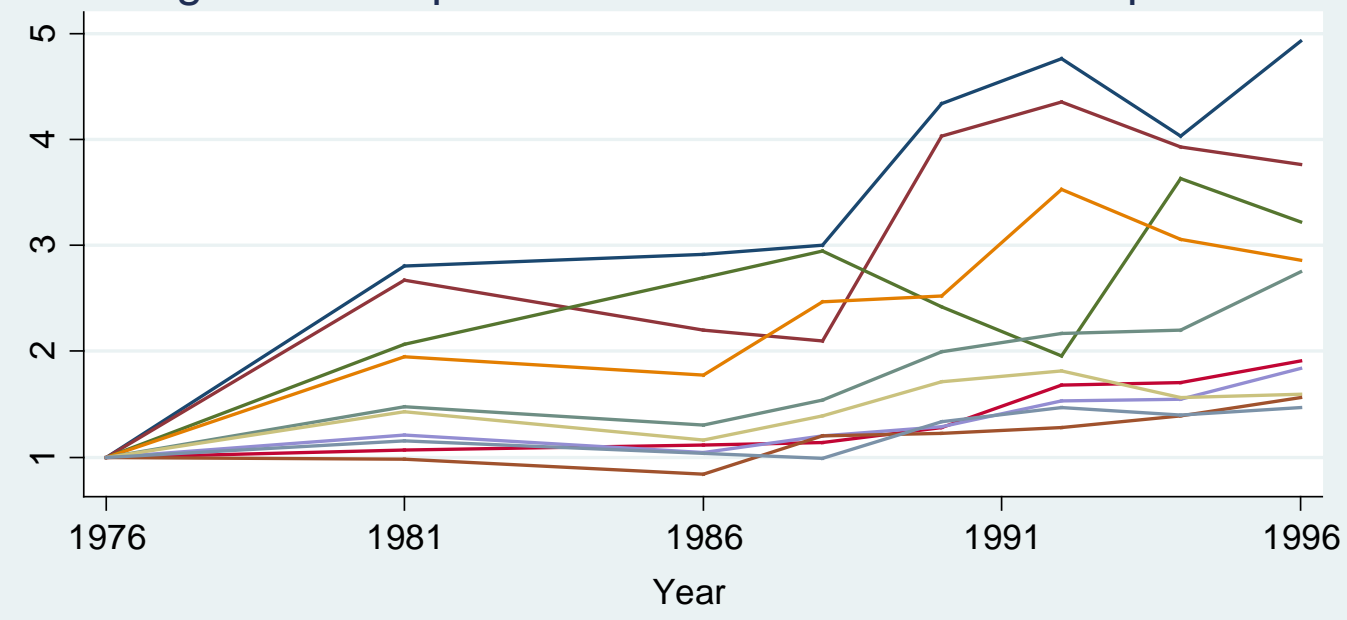

\begin{tabular}{|ll|}
\hline planning clerks & patternmakers/embroiders \\
non-grain food processors & managers \\
construction workers & medical workers \\
plumbers & bookkeepers \\
engineers & architects \\
\hline
\end{tabular}


Figure A3. Population Shares of Traditional Occupations

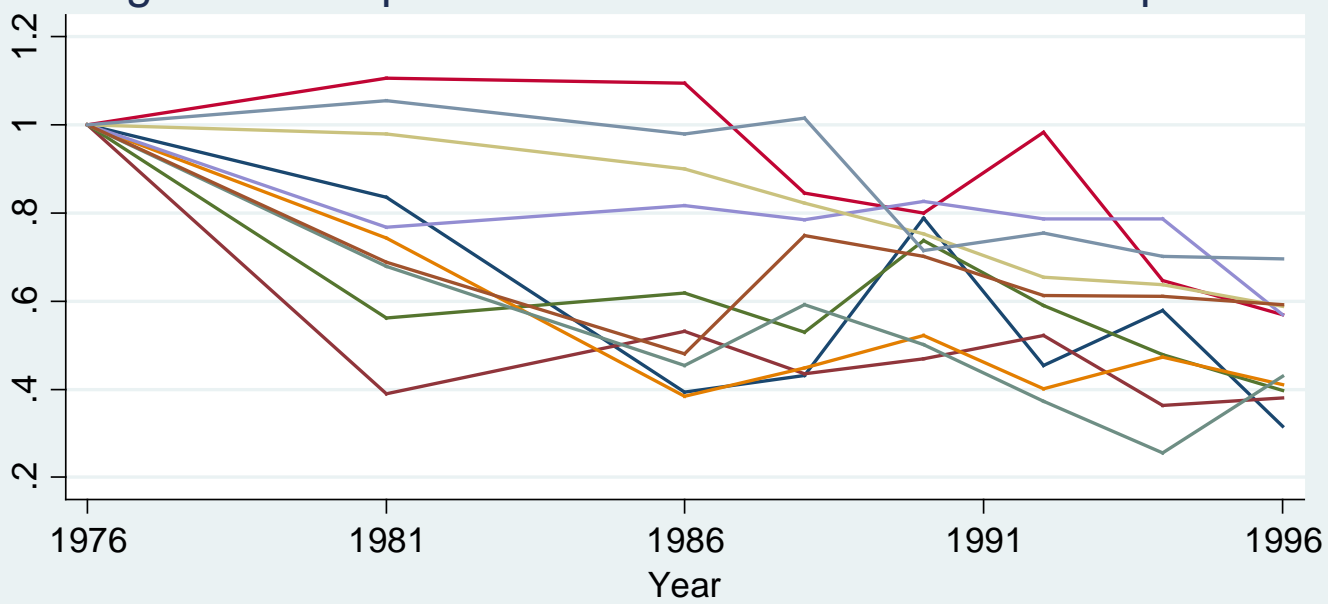

\begin{tabular}{|ll}
\hline stationary engine operators & other clerks \\
blacksmiths & postmasters \\
accountants & retail salesmen \\
taxi drivers & rice farmers \\
spinners/weavers & tailors/upholsters
\end{tabular}

Figure A4. Experience-Earnings Profiles

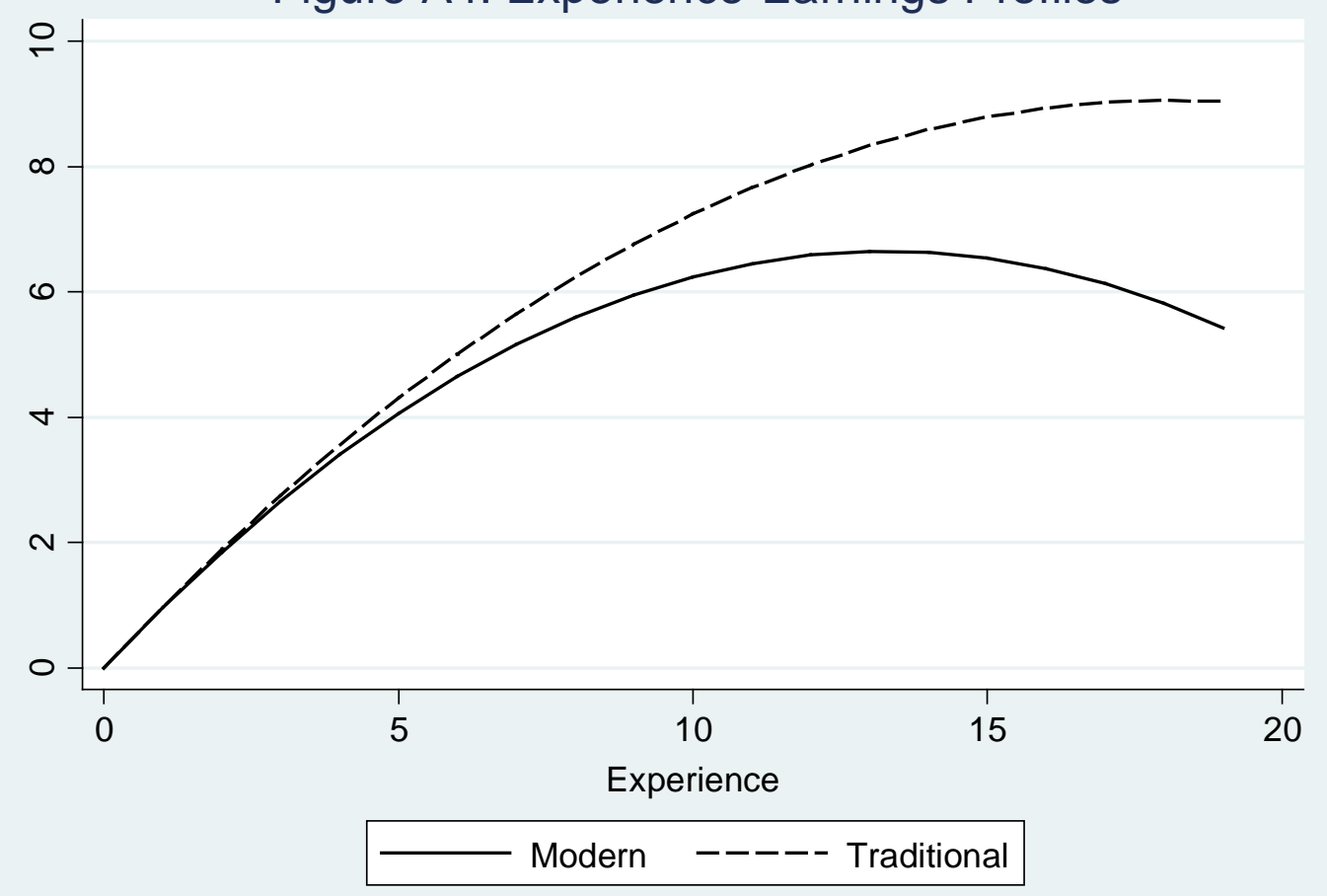




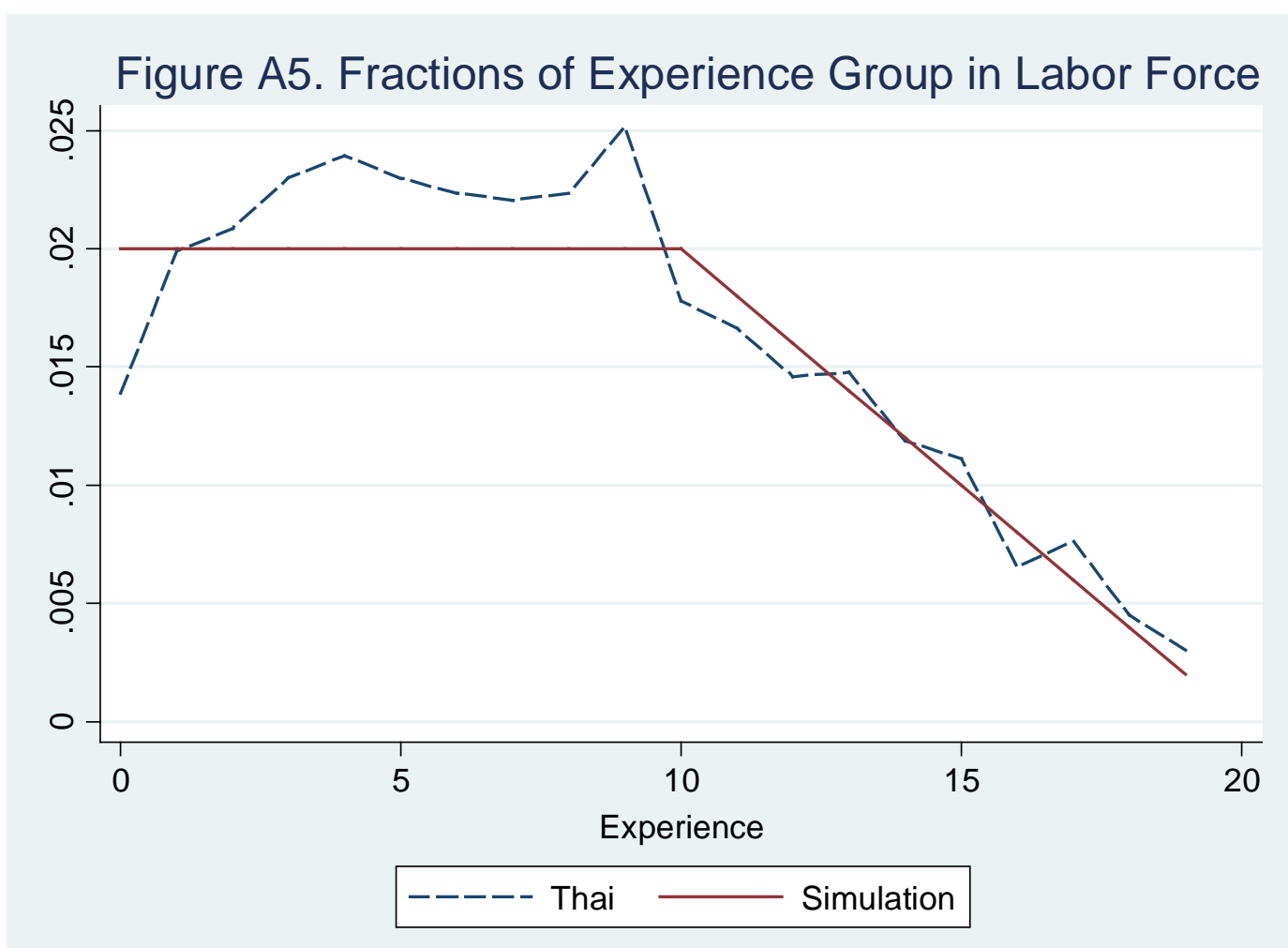

Figure A6. Sensitivity to Technology Level Gap

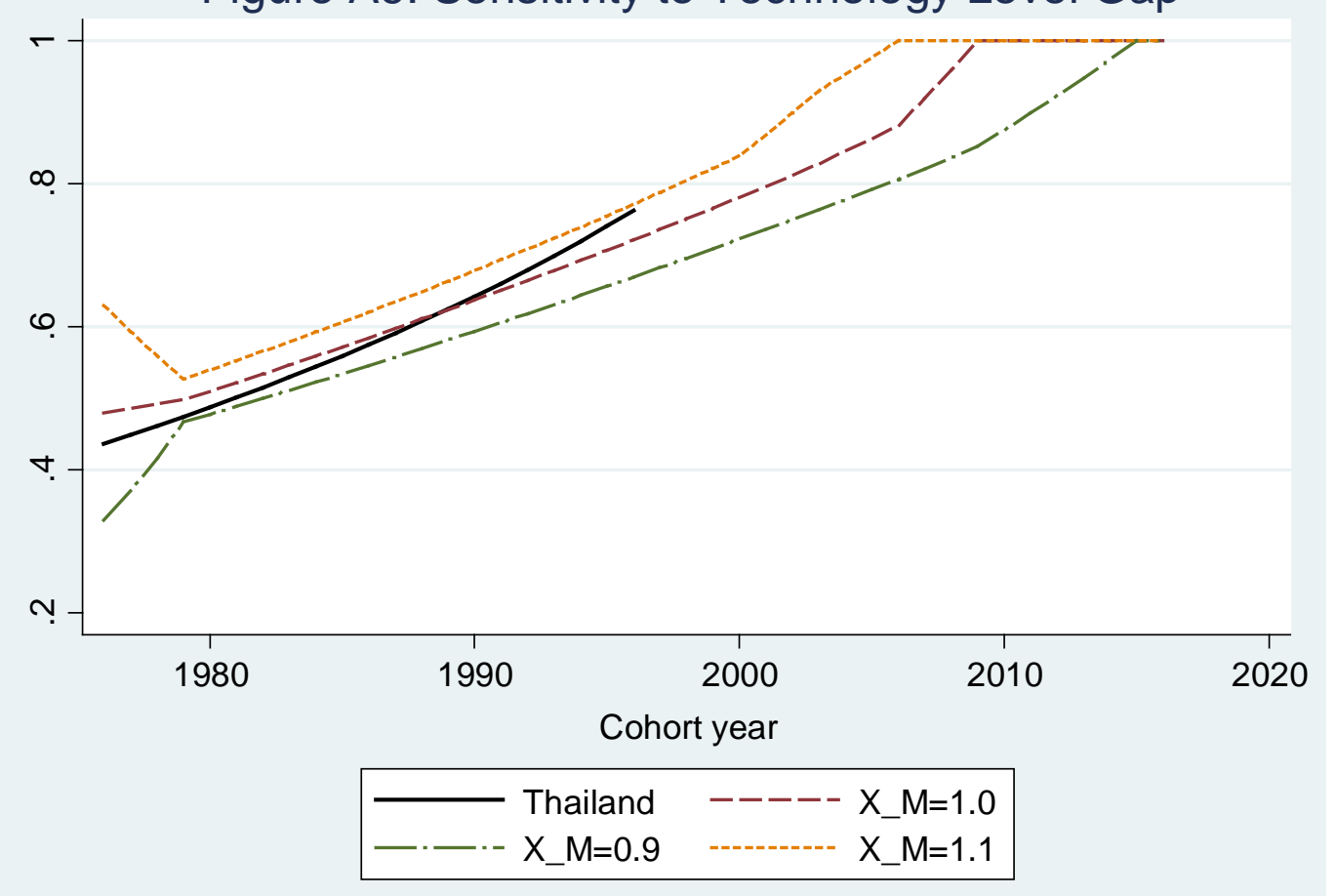


Figure A7. Sensitivity to Modern Technology Parameters
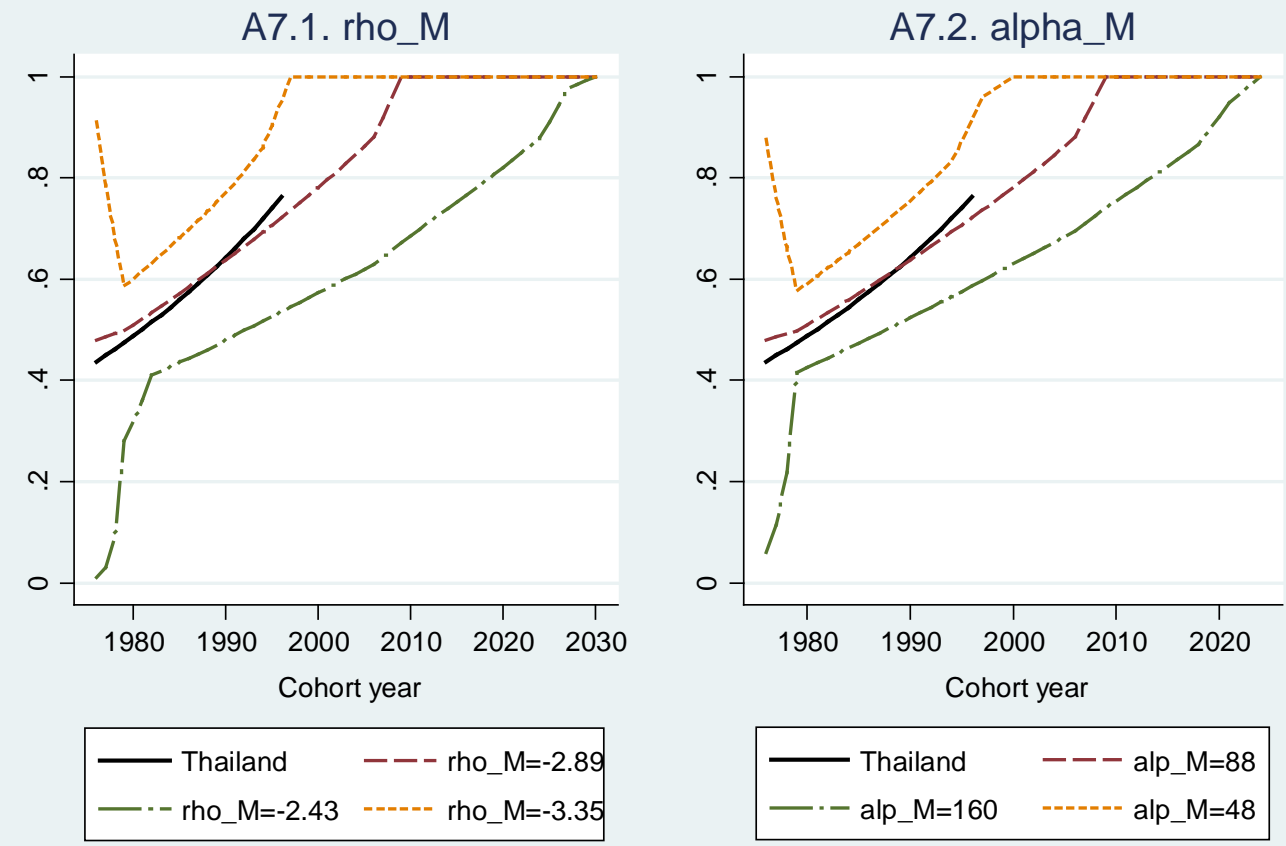

Figure A8. Sensitivity to Traditional Technology Parameters
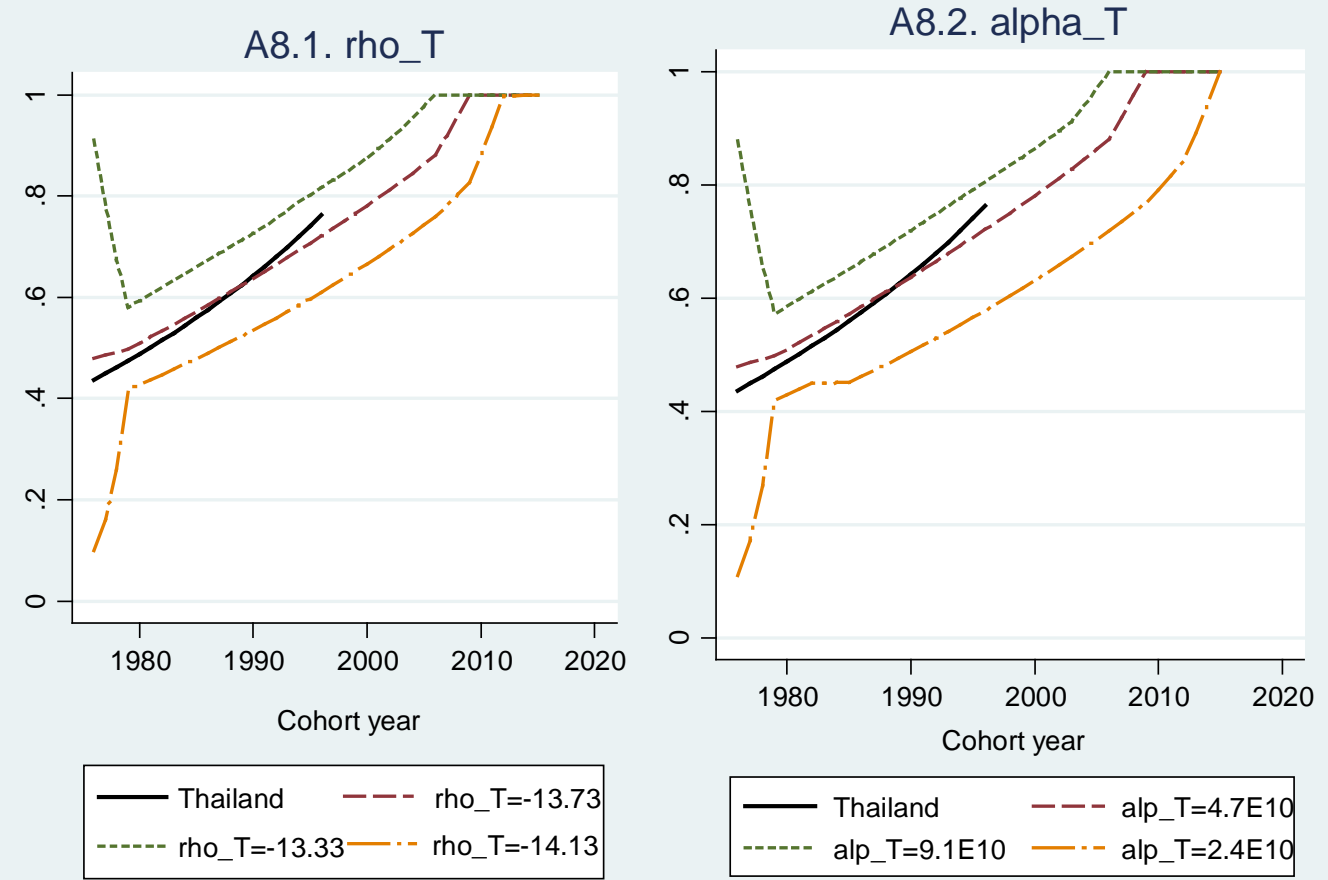